HEAT TRANSFER

Accepted $7^{\text {th }}$ June 2020

Editor: Dr. William M. Worek

Online ISSN:2688-4542

\title{
MELTING HEAT TRANSFER ANALYSIS OF ELECTRICALLY CONDUCTING NANOFLUID FLOW OVER AN EXPONENTIALLY SHRINKING/STRETCHING POROUS SHEET WITH RADIATIVE HEAT FLUX UNDER MAGNETIC FIELD
}

\author{
K. Venkatadri ${ }^{1 *}$, S. Abdul Gaffar ${ }^{2}$, V. Ramachandra Prasad ${ }^{3}$, B. Md. Hidayathulla Khan ${ }^{4}$ and O. Anwar Bég ${ }^{5}$ \\ ${ }^{I}$ Department of Mathematics, Sreenivasa Institute of Technology and Management studies, Chittoor-517127, India \\ ${ }^{2}$ Department of Information Technology, Mathematics Section, Salalah College of Technology, Salalah, Oman \\ ${ }^{3}$ Department of Mathematics, School of Advanced Sciences, Vellore Institute of Technology, Vellore - 6322014, India \\ ${ }^{4}$ Department of Mathematics, Sir Vishveshwaraiah Institute of Science and Technology, Madanapalle, India \\ ${ }^{5}$ Aeronautical and Mechanical Engineering Division, University of Salford, School of Science, Engineering and Environment \\ (SEE),M5 4WT, UK. \\ *Corresponding Author Email: venkatadri.venki@ gmail.com
}

\begin{abstract}
Modern magnetic nanomaterials processing operations are progressing rapidly and require increasingly sophisticated mathematical models for their optimization. Stimulated by such developments, in this article, a theoretical and computational study of steady magnetohydrodynamic (MHD) flow of nanofluid from an exponentially stretching/shrinking permeable sheet with melting (phase change) and radiative heat transfer is presented. Wall transpiration i.e. suction and blowing (injection) is included. Buongiorno's nanofluid model is deployed which simulates the effects of Brownian motion and thermophoresis. The transport equations and boundary conditions are normalized via similarity transformations and appropriate variables and similarity solutions are shown to depend on the transpiration parameter. The emerging dimensionless nonlinear coupled ordinary differential boundary value problem is solved numerically with the Newton-Fehlberg iteration technique. Validation with special cases from the literature is included. Increasing magnetic field i.e. Hartmann number is observed to elevate nanoparticle concentration and temperature whereas it damps the velocity. Higher values of melting parameter consistently decelerate the boundary layer flow and suppress temperature and nanoparticle concentration. Higher radiative parameter strongly increases temperature (and thermal boundary layer thickness) and weakly accelerates the flow. Increasing Brownian motion reduces nanoparticle concentrations whereas greater thermophoretic body force strongly enhances them. Nusselt number and Sherwood number are decreased with increasing Hartmann number whereas they are elevated with stronger wall suction and melting parameter.
\end{abstract}

KEYWORDS: Buongiorno nanofluid model; Convection heat transfer; magnetohydrodynamics; melting; suction/injection; thermal radiation; exponential stretching; Newton-Fehlberg iteration technique; electroconductive materials processing 


\section{NOMENCLATURE}

\begin{tabular}{|c|c|c|c|}
\hline$B_{0}$ & Transverse magnetic field & $U_{0}$ & Reference velocity \\
\hline$C_{p}$ & Specific heat & $u, v$ & $\begin{array}{l}\text { Dimensionless velocity components in } X \text { and } Y \\
\text { direction respectively }\end{array}$ \\
\hline$C$ & Nanoparticle volume fraction & $V(x)$ & Wall transpiration velocity \\
\hline$C_{f}$ & Skin friction coefficient & $V_{0}$ & Constant \\
\hline$D_{B}$ & Coefficient of Brownian diffusion & $X$ & Streamwise coordinate \\
\hline$D m$ & Mass diffusion & $Y$ & Transverse coordinate \\
\hline$D_{T}$ & Coefficient of thermophoretic diffusion & & \\
\hline$f$ & Dimensionless stream function & \multicolumn{2}{|c|}{ Greek Symbols } \\
\hline $\mathrm{Ha}$ & Hartmann magnetic number & $\alpha_{m}$ & Thermal diffusivity \\
\hline$g$ & Gravitational acceleration & $\tau$ & Ratio of nanofluid and base fluid heat capacity \\
\hline$k$ & Thermal conductivity of the fluid & $\beta$ & Volumetric volume expansion coefficient of the fluid \\
\hline$k^{*}$ & Mean absorption coefficient & $\sigma^{*}$ & Stefan-Boltzmann constant \\
\hline$M$ & Melting (phase change) parameter & $(\rho c)_{p}$ & Nanoparticles heat capacity \\
\hline $\mathrm{Nb}$ & Brownian motion parameter & $\sigma$ & Electric conductivity of the fluid \\
\hline$N t$ & Thermophoresis parameter & $\eta$ & $\begin{array}{l}\text { Similarity variable (dimensionless transverse } \\
\text { coordinate) }\end{array}$ \\
\hline $\mathrm{Nu}$ & Nusselt number & $(\rho c)_{f}$ & Base fluid heat capacity \\
\hline $\operatorname{Pr}$ & Prandtl number & $\mu_{f}$ & Dynamic viscosity \\
\hline$R$ & Radiation parameter & $\psi$ & Non-dimensional stream function \\
\hline$T$ & Fluid temperature & $v$ & Kinematic viscosity \\
\hline$T_{0}$ & Reference temperature & $\phi$ & Dimensionless concentration \\
\hline Le & Lewis number & $\rho$ & Fluid density of the nanoparticles \\
\hline$S$ & Transpiration parameter & $\theta$ & Dimensionless temperature \\
\hline$S h$ & Sherwood number & & Subscripts \\
\hline$q_{r}$ & Radiative heat flux & $w$ & Conditions on the wall \\
\hline$U$ & Velocity of shrinking sheet & $\infty$ & Free stream condition \\
\hline & & & \\
\hline
\end{tabular}

\section{INTRODUCTION}

In the past few decades significant progress has been made in deploying nanomaterials in science and technology. These materials which are engineered at the nanoscale constitute an important aspect of nanotechnology which has successfully achieved improvements in energy enhancement in many industries. Electron energy increases with a decrease of grain size. This phenomenon has also been exploited in fluid dynamics for enhancement in heat transfer. The nanoscale particles (metallic or non-metallic) are embedded in conventional base liquids (or gases) create a solid-liquid mixture called nanofluid. The nano-sized particles (fewer than $100 \mathrm{~nm}$ in dimensions) are suspended in a liquid uniformly and the resulting colloidal suspension can be stabilized with various techniques. The term "nanofluid" was first introduced by Choi [1] who 
synthesized colloidal metallic nanoparticle suspensions in base fluids and demonstrated that the overall thermal conductivity of engineering fluids can be substantially elevated due to high thermal conductivity of metals without agglomeration or clustering effects. Buongiorno [2] theoretically studied the influence of nanoparticle dispersion on the energy transfer of nanofluids and suggested a non-homogeneous two-component model. In this model, a slip velocity in the base fluid is developed by the nanoparticles. Other effects identified include inertia, Brownian diffusion, thermophoresis, diffusion-phoresis, Magnus effect, fluid drainage and gravity (settlement and sedimentation). Amongst these only Brownian diffusion and thermophoresis are emphasized in the Buongiorno model in which the time taken by the nanoparticle to diffuse is defined over a length equal to the nanoparticle diameter. Micro-convection around the nanoparticle and ballistic collisions between nanoparticles are also important in this model and the thermal conductivity and the single-phase heat transfer coefficients of the nanofluid are higher than the base fluids. Yang et al [3] revised the Buongiorno nanofluid model to study the nanoparticle volume fraction effect. In the revised model the nanoparticle migration effect is suitably considered to control the nanoparticle volume fraction at the boundary (wall). Nanofluids have found extremely diverse applications in for example, cooling of automotive engines, electronic components, transformer oils, medicine, smart coatings and solar collectors. Computational nanofluid dynamics has also grown into a substantial subject in the $21^{\text {st }}$ century. Many numerical methods and Multiphysics simulations of nanofluids have been reported. Abdul Gaffar et al. [4] used a finite difference method and two-phase model to study hydromagnetic nanofluid flow from a circular cylinder in a non-Darcian porous medium. Abdullah et al [5] investigated the thermally radiative magnetoconvection flow of a Sisko non-Newtonian nanofluid from a stretching sheet with non-linear chemical reaction using an explicit finite difference technique. Rosca et al [6] explored the unsteady stagnation-point flow and heat transfer at an impermeable stretching/shrinking sheet in a copper-water nanofluid using the bvp4c quadrature in MATLAB. They observed that the solution is unique for a stretching sheet, whereas for a shrinking sheet, dual solutions are observed. Srinivasacharya et al [7] analyzed the mixed convective nanofluid flow between two concentric cylinders with Joule electrical dissipation, noting that the entropy generation, temperature and velocity are intensified with Joule effect.

The flow from a stretching/shrinking sheet is a fundamental problem in materials processing and other industrial operations. Known as Sakiadis flow, it arises in film condensation 
processes, crystal growth, aerodynamic extrusion of plastic sheets, metallic sheet cooling in baths, vapour deposition control in chemical processing equipment, shrink fit wrapping, corrosion protection via smart films, polymer stretching etc. Sakiadis flows are popular also among researchers since they use the framework of boundary layer theory which reduces the NavierStokes equations (elliptic) to parabolic equations and permit both analytical and computational solutions to be derived much more easily. In porous sheets where lateral mass flux (transpiration i.e. blowing or suction) transverse to the sheet surface is utilized to achieve flow control, the stretching sheet creates a far field suction towards the sheet whereas the opposite flow behavior is seen in the case of a shrinking sheet. Additionally, the sheet stretch/shrink rate may be linear, quadratic, cubic, exponential etc. Multiple physical effects may also arise including magnetohydrodynamics, heat and mass diffusion, cross diffusion, multi-mode heat transfer, viscous and Ohmic dissipation, surface tension etc. Najiyah et al [8] examined the combined effects of double stratification and buoyancy forces on nanofluid flow past a shrinking/stretching sheet using a non-Fourier heat flux model (with thermal relaxation effects included). They observed that an increase in the wall mass suction generates dual solutions. Sreenivasulu et al [9] studied the radiative magnetohydrodynamic (MHD) convection slip flows of viscous fluid from an exponentially stretching sheet with Joule heating and viscous dissipation, highlighting that the fluid velocity fluctuates significantly with wall slip effects. Atual et al [10] implemented the homotopy analysis method to investigate the unsteady laminar MHD bio-convection flow of Casson thin film with uniform thickness over a stretching sheet in the presence of viscous dissipation. They observed that increasing velocity slip reduces the shear stress rate and mass transfer rate whereas it enhances heat transfer rate. Ghosh et al [11] studied the flow and heat transfer in nanofluid boundary layer flow from an exponentially shrinking porous sheet, observing that the variations in heat and mass fluxes strongly modify the temperature and nanofluid volume fraction.

Magnetohydrodynamic (MHD) flows with heat transfer have also gained prominence among researches since they abound in many modern industrial processes. Examples include MHD wave energy systems, plasma heat transfer control in nuclear reactors, liquid metal casting, levitation bubble dynamics, semiconductor melt fabrication, magnetically actuated lubrication of wind turbines, robots and roller coasters etc. MHD is an enormous subject which features many complex phenomena including static magnetic fields, alternating magnetic fields, magnetic 
induction generation with aligned magnetic fields, magnetic vorticity, Maxwell displacement currents, laminar and turbulent flow, free surface flow, MHD waves etc. The use of a transverse static magnetic field remains a popular method in flow control of electrically conducting fluent media. It has therefore been studied extensively by engineers and mathematicians, most recently for the emerging subset of novel magnetic nanofluids. These contain magnetic nanoparticles (often iron-based) which render the nanofluid suspension to be electrically conducting and responsive to an external magnetic field. Raju et al [12] addressed the double stratification effects on unsteady natural MHD flow of viscoelastic nanofluid in a rectangular channel with heat and mass flux. They studied the effects of magnetic field, nonlinear convection, Brownian motion and thermophoresis on heat, momentum and concentration characteristics. Khan et al [13] computed the entropy generation in non-Newtonian hydromagnetic dissipative nanofluid flow from a stretching sheet with heat source/sink and chemical reaction effects. They observed that the entropy generation rate is enhanced with a rise in Brinkman (viscous dissipation) number. Devi and Suriyakumar [14] studied hydromagnetic Blasius and Sakiadis flows of nanofluids from tilted surfaces using bvp4c algorithms and noted that an increase in magnetic field enhances velocity and shear stress rate while it reduces heat transfer rate.

Melting fluid dynamics and heat transfer is another complex and important area of thermophysics and is related to phase change problems that arise in manufacturing processes such as laser ablation, polymer synthesis, metallic processing and electromagnetic crucible systems and glass treatment. Melting heat transfer simulation is complex in thermally driven flows since the fluid dynamics has to be coupled with a moving interface. Such problems are often termed "Stefan moving boundary" problems. The melting front position and Nusselt number are the important variables in melting heat transfer process calculations. To solve melting heat transfer problems efficiently and accurately as moving boundary problems, powerful computational techniques are required. However, an alternative approach is to simulate the melting effect as a boundary condition which circumvents the need to simulate the moving interface explicitly. This approach is also compatible with boundary layer flow models and although it is less accurate, it does provide a good approximation for the wall heat transfer rates. Amirsom et al [15] investigated the phase change magnetohydrodynamic bio-nanofluid convection flow from a stretching sheet with second order slip using bvp4c quadrature. They observed that increasing melting heat transfer parameter (i.e. stronger phase change effect) reduces heat transfer rate at the sheet surface. Hayat et al [16] 
examined the melting magneto-convective rheological nanofluid flow from a stretching sheet with Joule heating and viscous dissipation using an optimal homotopy analysis method and noting that heat transfer rate is suppressed with melting parameter whereas it is elevated with viscoelastic (Deborah) number and thermophoresis parameter. Waqar et al [17] addressed the melting heat and mass transfer characteristics of Burgers fluids in stretching sheet flow with nonlinear radiative heat flux. They observed that increasing melting parameter decreases temperature. Feroz et al [18] presented a study of melting heat transfer in radiative magnetohydrodynamic Sisko nanofluid flow from a linearly stretching sheet using a collocation method. They observed that the shear stress rate decreases with an increase in melting parameter.

In high temperature industrial fabrication of magnetic nanomaterials [19, 20], the collective effects of melting and radiative heat transfer, magnetohydrodynamics and nanoscale fluid dynamics arise. Therefore, in the present study we analyze the steady viscous melting heat transfer in magnetohydrodynamic forced convection flow of an electrically conducting nanofluid from a stretching/shrinking sheet with wall transpiration and radiative heat transfer. The NewtonFehlberg iteration technique is utilized to solve the transformed non-dimensional boundary layer equations with wall and free stream boundary conditions. The influences of Hartmann number $(\mathrm{Ha})$, Brownian motion $(\mathrm{Nb})$, thermophoresis $(\mathrm{Nt})$, melting heat parameter $(\mathrm{M})$, radiation parameter $(R)$, Prandtl number (Pr), suction/injection parameter $(S)$ and Lewis number $(L e)$ on the relevant flow variables are described in detail. Validation with earlier studies is also included.

\section{MATHEMATICAL MODEL}

Consider the steady forced convection boundary layer flow of nanofluid over an exponentially shrinking sheet in presence of melting (Fig. 1). The $x$-axis is directed along the stretching surface and $y$-axis normal to it. The flow is restricted to $y>0$ and two equal and opposite forces are applied along the $x$-axis so that the wall is stretched keeping the origin fixed. A uniform magnetic field, $\mathrm{B}_{\mathrm{o}}$, is applied normal to the sheet. Magnetic Reynolds number is assumed to be small and magnetic induction is therefore neglected. The governing equations of motion may be written [15] as:

$\frac{\partial u}{\partial x}+\frac{\partial v}{\partial y}=0$ 


$$
\begin{aligned}
& u \frac{\partial u}{\partial x}+v \frac{\partial u}{\partial y}=\frac{1}{\rho} \frac{\partial}{\partial y}\left(\mu_{f} \frac{\partial u}{\partial y}\right)-\frac{\sigma B_{0}^{2}}{\rho} u \\
& \left(u \frac{\partial T}{\partial x}+v \frac{\partial T}{\partial y}\right)=\alpha_{m} \frac{\partial^{2} T}{\partial y^{2}}+\tau\left(D_{B} \frac{\partial T}{\partial y} \frac{\partial C}{\partial y}+\frac{D_{T}}{T_{\infty}}\left(\frac{\partial T}{\partial y}\right)^{2}\right)+\frac{16 \sigma^{*} T_{\infty}^{3}}{3 k^{*}} \frac{\partial^{2} T}{\partial y^{2}} \\
& u \frac{\partial C}{\partial x}+v \frac{\partial C}{\partial y}=D_{B} \frac{\partial^{2} C}{\partial y^{2}}+\frac{D_{T}}{T_{\infty}} \frac{\partial^{2} T}{\partial y^{2}}
\end{aligned}
$$

Transverse magnetic field, $\mathrm{B}_{\mathrm{o}}$

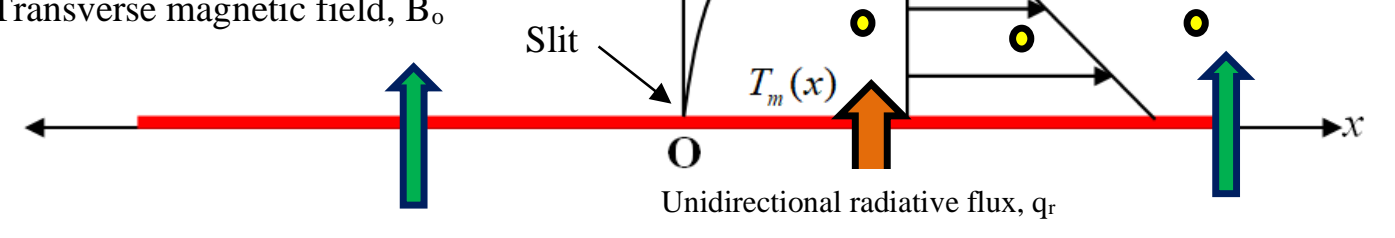

Fig 1. Schematic of problem

Here $\tau=\frac{\left(\rho c_{p}\right)_{p}}{\left(\rho c_{p}\right)_{f}}$. The boundary conditions at the wall (sheet) and in the free stream (edge of the boundary layer) are:

$$
\begin{aligned}
& u=U, v=-V(x), T=T_{m}, k\left(\frac{\partial T}{\partial y}\right)_{y=0}=\rho\left(\lambda+c_{s}\left(T_{m}-T_{0}\right)\right) v(x, 0), C=C_{m} \text {, at } y=0 \\
& u \rightarrow 0, \quad T \rightarrow T_{\infty}, \quad C \rightarrow C_{\infty}, \text { at } y=\infty
\end{aligned}
$$

Here $U=-U_{0} e^{\frac{x}{L}}$ is the stretching/shrinking velocity and $V(x)=V_{0} e^{\frac{x}{2 L}}$ is the wall transpiration velocity i.e. suction for $V(x)>0$ and blowing (injection) for $V(x)<0$.

The following are introduction of similarity transformations. 


$$
\begin{aligned}
& \eta=y \sqrt{\frac{U_{0}}{2 v L}} \exp \left(\frac{x}{2 L}\right), \quad \psi=\sqrt{2 v L U_{0}} f(\eta) \exp \left(\frac{x}{2 L}\right), T-T_{\infty}=\frac{q_{r}}{\alpha} T_{0} \theta(\eta) \exp \left(\frac{x}{2 L}\right) \\
& C-C_{\infty}=\frac{q_{r}}{D_{B}} C_{0} \phi(\eta) \exp \left(\frac{x}{2 L}\right), \quad H a=\frac{\sigma B_{0}^{2}}{\rho c_{p}}, \quad L e=\frac{v}{D_{B}}, \quad N b=\frac{D_{B} \tau C_{0}}{v} \\
& N t=\frac{D_{T} \tau T_{0}}{T_{\infty} \alpha \nu}, \quad S=V \sqrt{\frac{2 L}{v U_{0}}}, \quad M=\frac{c_{p}\left(T_{m}-T_{\infty}\right)}{\lambda+c_{s}\left(T_{m}-T_{0}\right)}, \quad \alpha_{m}=\frac{k_{m}}{(\rho c)_{f}}
\end{aligned}
$$

Using a dimensional stream function $\psi$, defined as $u=\frac{\partial \psi}{\partial y}, \quad v=-\frac{\partial \psi}{\partial x}$, and implementing (6) in Eqns.(1)-(5), the emerging similarity boundary layer equations are:

$f^{\prime \prime \prime}+f f "-2 f^{\prime 2}-H a f^{\prime}=0$

$\frac{1}{\operatorname{Pr}}\left(1+\frac{4 R}{3}\right) \theta^{\prime \prime}+f \theta^{\prime}-f^{\prime} \theta+N b \theta^{\prime} \phi^{\prime}+N t \theta^{\prime 2}=0$

$\phi^{\prime \prime}+L e\left(f \phi^{\prime}-f^{\prime} \phi\right)+\frac{N t}{N b} \theta^{\prime \prime}=0$

The boundary conditions for these equations are imposed as:

$$
\left.\begin{array}{l}
\operatorname{Pr} f(0)+M \theta^{\prime}(0)=0, \quad f^{\prime}(0)=S, \quad \theta(0)=1, \quad \phi(0)=1 \\
f^{\prime}(\infty)=0, \quad \theta(\infty)=0, \quad \phi(\infty)=0
\end{array}\right\}
$$

All terms are defined in the nomenclature. Here $S>0$ corresponds to mass suction and $S<0$ corresponds to mass injection.

\section{NUMERICAL SOLUTION}

The coupled, nonlinear multi-degree two-point boundary value problem defined in the Eqns. (7)-(10) is integrated by using Runge-Kutta-Fehlberg method coupled with a shooting method. The asymptotic boundary conditions at $\eta \rightarrow \infty$ are replaced by those at $\eta \rightarrow 8$ in such a way that the far field condition is satisfied asymptotically, and smooth accurate solutions are generated into the free stream. The solution procedure involves the following steps:

Step 1: Develop the initial value problem version of the two-point boundary value problem. 
Step 2: Guess missing initial conditions by an iterative process (shooting technique).

Step 3: Refine the guessed values using the Newton-Raphson method until the boundary conditions are satisfied.

Step 4: Solve the reduced system of the initial value equations simultaneously by Runge-Kutta Fehlberg method by taking a step size $h=0.001$.

Step 5: Step 4 is repeated until the required accuracy is achieved $\left(10^{-6}\right)$.

\section{NUMERICAL VALIDATION}

The present results for Nusselt number i.e. local heat transfer rate, $-\theta^{\prime}(\xi, 0)$ are compared with earlier solutions of Ishak [21] (by neglecting melting and nanofluid effects in the present model i.e. setting $M=0, N b=0, N t=0$ ) and Swati and Gorla [22] (by neglecting slip effects in [22] and melting and nanofluid effects in the present model i.e. setting $M=0, N b=0, N t=0$ ) for various values of Prandtl number $(\mathrm{Pr})$ and the comparisons are presented in Table 1. Very close excellent agreement is obtained and therefore confidence in the iterative Newton- Fehlberg code is high.

Table 1: Comparison values of heat transfer rate, $-\theta^{\prime}(0)$ with $M=0, N b=0, N t=0$ for different values of $\operatorname{Pr}$.

\begin{tabular}{|c|c|c|c|}
\hline$P r$ & Ishak [21] & Swati and Gorla [22] & Present \\
\hline 1 & 0.9548 & 0.9547 & 0.9550 \\
\hline 2 & 1.4715 & 1.4714 & 1.4715 \\
\hline 3 & 1.8691 & 1.8691 & 1.5692 \\
\hline 5 & 2.5001 & 2.5001 & 2.4999 \\
\hline 10 & 3.6604 & 3.6603 & 3.6602 \\
\hline
\end{tabular}

\section{RESULTS AND DISCUSSION}

In this section, extensive graphical results (Figs. 2-19) obtained with the iterative NewtonFehlberg method are presented for the influence of selected parameters (Prandtl number (Pr), melting parameter $(M)$, Hartmann number $(H a)$, suction parameter $(S)$,radiation parameter $(R)$, nanoparticle Brownian motion parameter $(\mathrm{Nb})$ and thermophoresis parameter $(\mathrm{Nt})$ ) on velocity, 
temperature, nanoparticle volume fraction concentration versus transverse coordinate $(\eta)$. Furthermore solutions are also given for heat transfer coefficient (local Nusselt number) $\left(-\theta^{\prime}(0)\right)$ and nanoparticle volume fraction coefficient (local Sherwood number) $\left(-\phi^{\prime}(0)\right)$ in Table 2 for different values of $P r, S, N t, N b, L e, H a, M$ and $R$. Clearly, an increase in $\left(-\theta^{\prime}(0)\right)$ and a decrease in $\left(-\phi^{\prime}(0)\right)$ is observed at the sheet surface $(\eta=0)$ for various values of $\operatorname{Pr}$. With increasing $\operatorname{Pr}$, the values of $\left(-\theta^{\prime}(0)\right)$ significantly increase whereas the values of $\left(-\phi^{\prime}(0)\right)$ decrease. Heat transfer to the sheet is therefore increased with lower thermal conductivity (higher Prandtl number) whereas nanoparticle diffusion (mass transfer) is suppressed. A similar tendency has been observed by Prasad et al. [23]. Further, it is seen that $\left(-\theta^{\prime}(0)\right)$ and $\left(-\phi^{\prime}(0)\right)$ decrease with stronger magnetic field i.e Hartmann number, Ha. Stronger magnetic field energizes the fluid and draws heat away from the boundary leading to a decrease in heat transfer to the wall. This also adversely affects the nanoparticle diffusion to the wall. However, $\left(-\theta^{\prime}(0)\right)$ and $\left(-\phi^{\prime}(0)\right)$ are observed to enhance with increasing wall transpiration $(S)$ and melting $(M)$ values since stronger wall suction and phase change effect (melting intensity) damps the flow and this serves to inhibit heat and nanoparticle diffusion into the boundary layer i.e. it encourages heat and nanoparticle mass transfer to the boundary away from the nanofluid. Also $\left(-\theta^{\prime}(0)\right)$ is seen to decrease with increasing $R$ values since radiation energizes the nanofluid and this causes migration of heat away from the boundary and a thinner thermal boundary layer. However, $\left(-\phi^{\prime}(0)\right)$ is increased with stronger radiation, implying that nanoparticle diffusion to the boundary is elevated and nanoparticle concentration boundary layer is decreased.

Figs. 2 - 4 display the profiles for velocity, temperature and concentration for different $\mathrm{Pr}$ values. The velocity is very slightly increased with an increase in $P r$. There is therefore a corresponding decrease in the thickness of the momentum boundary layer. A significant reduction in temperature profiles is observed with an increase in $\operatorname{Pr}$ values. Increasing $\operatorname{Pr}$ relates to weak thermal diffusivity and reduced thermal conductivity of the magnetic nanofluid. Hence the thermal boundary layer thickness is reduced. This is a classical feature of convection heat transfer as noted in Incropera and DeWitt [24] and Schlichting [25]. However, the nanoparticle volume fraction is 
boosted with an increase in $\operatorname{Pr}$ values, implying that mass diffusion is assisted with lower thermal conductivity and nanoparticle species boundary layer thickness is increased.

Table 2:Numerical computation for Local Nusselt number $-\theta^{\prime}(0)$, local Sherwood number $\phi^{\prime}(0)$ for $\operatorname{Pr}, S, N t, N b, L e, H a, M$ and $R$.

\begin{tabular}{|l|l|l|l|l|l|l|l|l|l|}
\hline$P r$ & $S$ & $N t$ & $N b$ & $L e$ & $H a$ & $M$ & $R$ & $-\theta^{\prime}(0)$ & $\phi^{\prime}(0)$ \\
\hline 0.7 & 1.0 & 0.5 & 0.5 & 1.3 & 5 & 0.1 & 0.5 & 0.338193 & 0.698745 \\
\hline 0.025 & & & & & & & & 0.177221 & 1.504087 \\
\hline 0.054 & & & & & & & & 0.184539 & 1.119524 \\
\hline 10 & & & & & & & & 1.241506 & -0.148668 \\
\hline 0.7 & 1.0 & 0.5 & 0.5 & 1.3 & 10 & 0.1 & 0.5 & 0.295645 & 0.603538 \\
\hline & & & & & 15 & & & 0.272460 & 0.548534 \\
\hline 0.7 & 2 & 0.5 & 0.5 & 1.3 & 5 & 0.1 & 0.5 & 0.503074 & 1.069706 \\
\hline & 4 & & & & & & & 0.769484 & 1.630093 \\
\hline & 6 & & & & & & & 0.984079 & 2.067769 \\
\hline & 8 & & & & & & & 1.166528 & 2.436736 \\
\hline 0.7 & 1.0 & 0.5 & 0.5 & 1.3 & 5 & 0.5 & 0.5 & 0.378854 & 0.844536 \\
\hline & & & & & & 1.0 & & 0.461487 & 1.126282 \\
\hline & & & & & & 1.5 & & 0.643332 & 1.705811 \\
\hline 0.7 & 1.0 & 0.5 & 0.5 & 1.3 & 5 & 0.1 & 1.0 & 0.290749 & 0.739472 \\
\hline & & & & & & & 1.5 & 0.263858 & 0.762556 \\
\hline & & & & & & & 2.0 & 0.246546 & 0.777413 \\
\hline
\end{tabular}

Figs. 5 - 7 depicts the profiles for velocity, temperature and nanoparticle volume fraction for various melting parameter $(M)$ values. An increase in $M$ is observed to decrease the velocity profiles slightly. Physically, a change in the melting parameter causes an exacerbation in molecular movement but simultaneously a phase change in the nanofluid. This delays the momentum diffusion in the boundary layer and decelerates the flow with a thickening in momentum (hydrodynamic) boundary layer thickness. It is also found that the profiles for temperature and nanoparticle volume fraction decrease and the corresponding thermal and concentration boundary layer thickness are also reduced with greater $M$ values. Enhanced melting therefore inhibits all diffusion types in the boundary layer i.e. momentum, thermal and nanoparticle species and neglection of this effect in materials processing simulations leads to an over-estimate in velocity, temperature and nanoparticle volume fraction characteristics. 


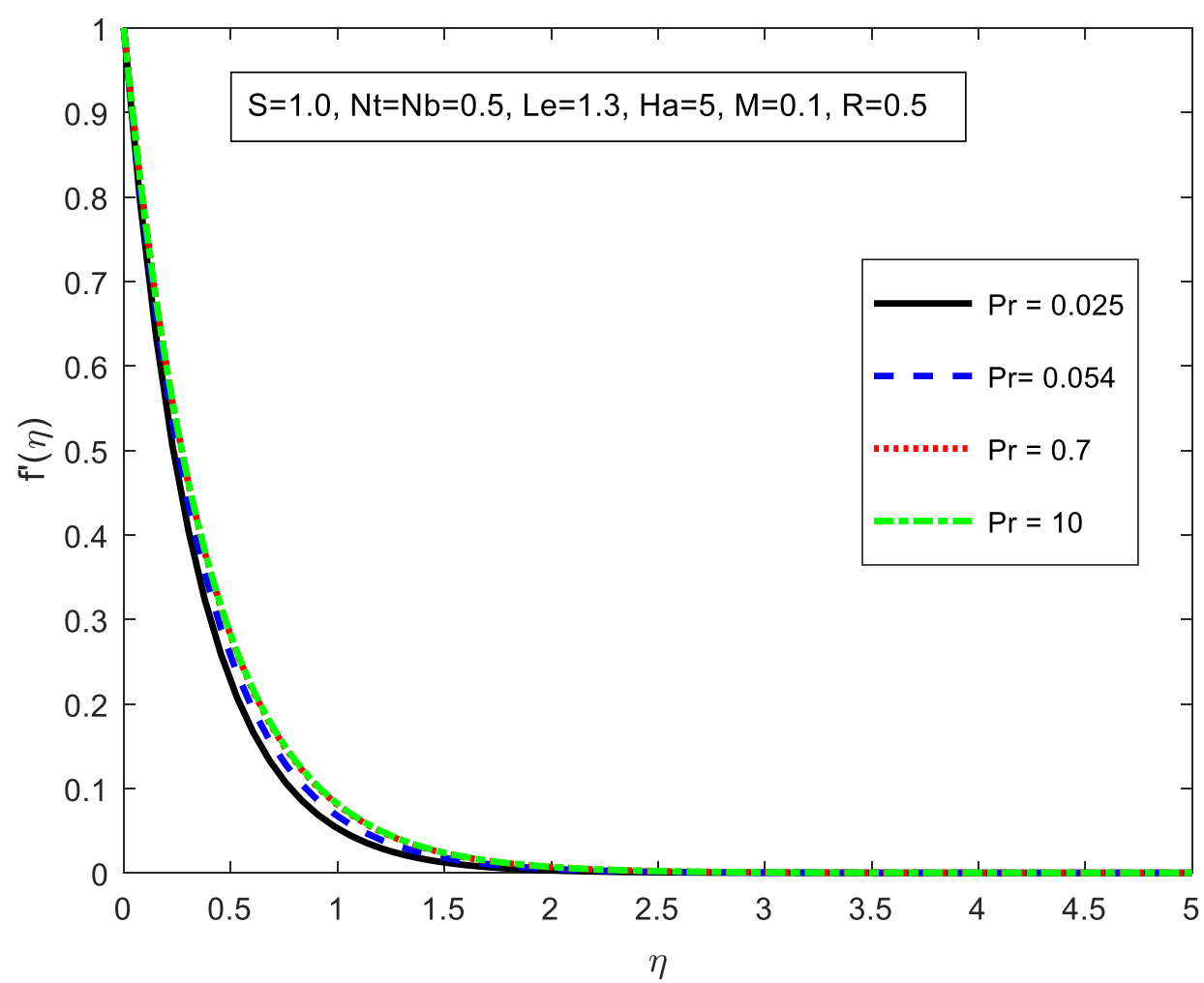

Fig 2. Influence of $\operatorname{Pr}$ on Velocity Profiles

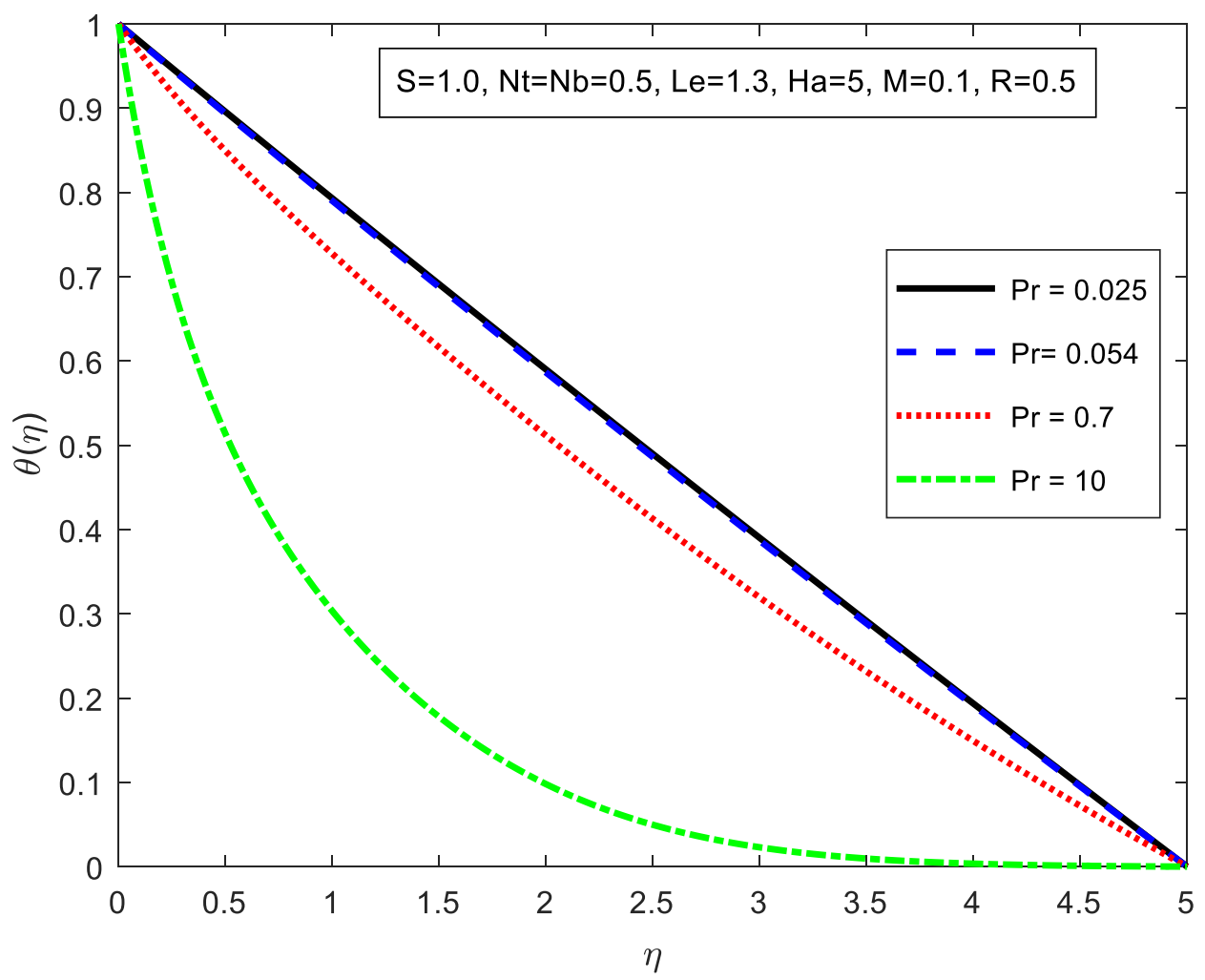

Fig 3. Influence of $\operatorname{Pr}$ on Temperature Profiles 


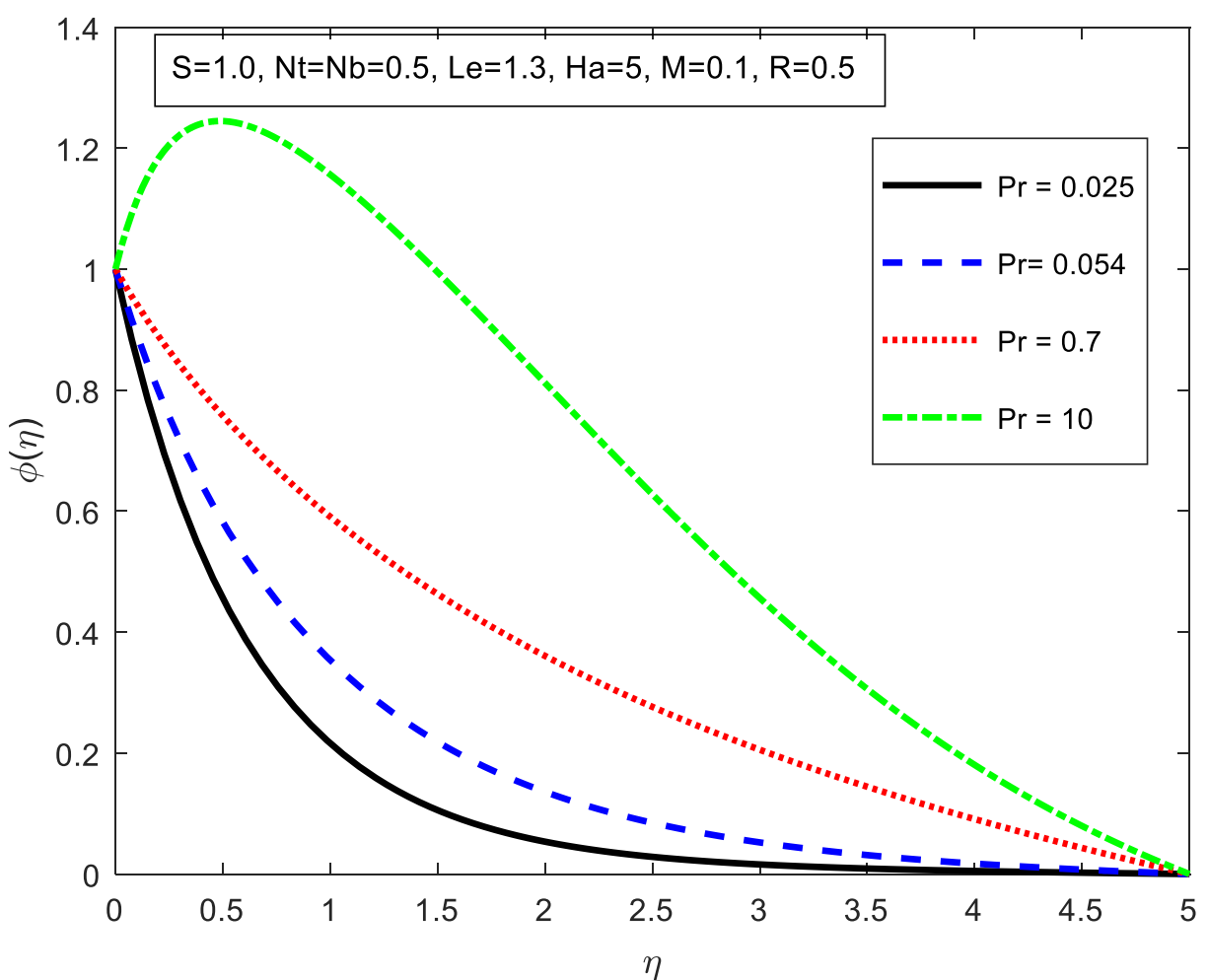

Fig 4. Influence of $\operatorname{Pr}$ on Concentration Profiles

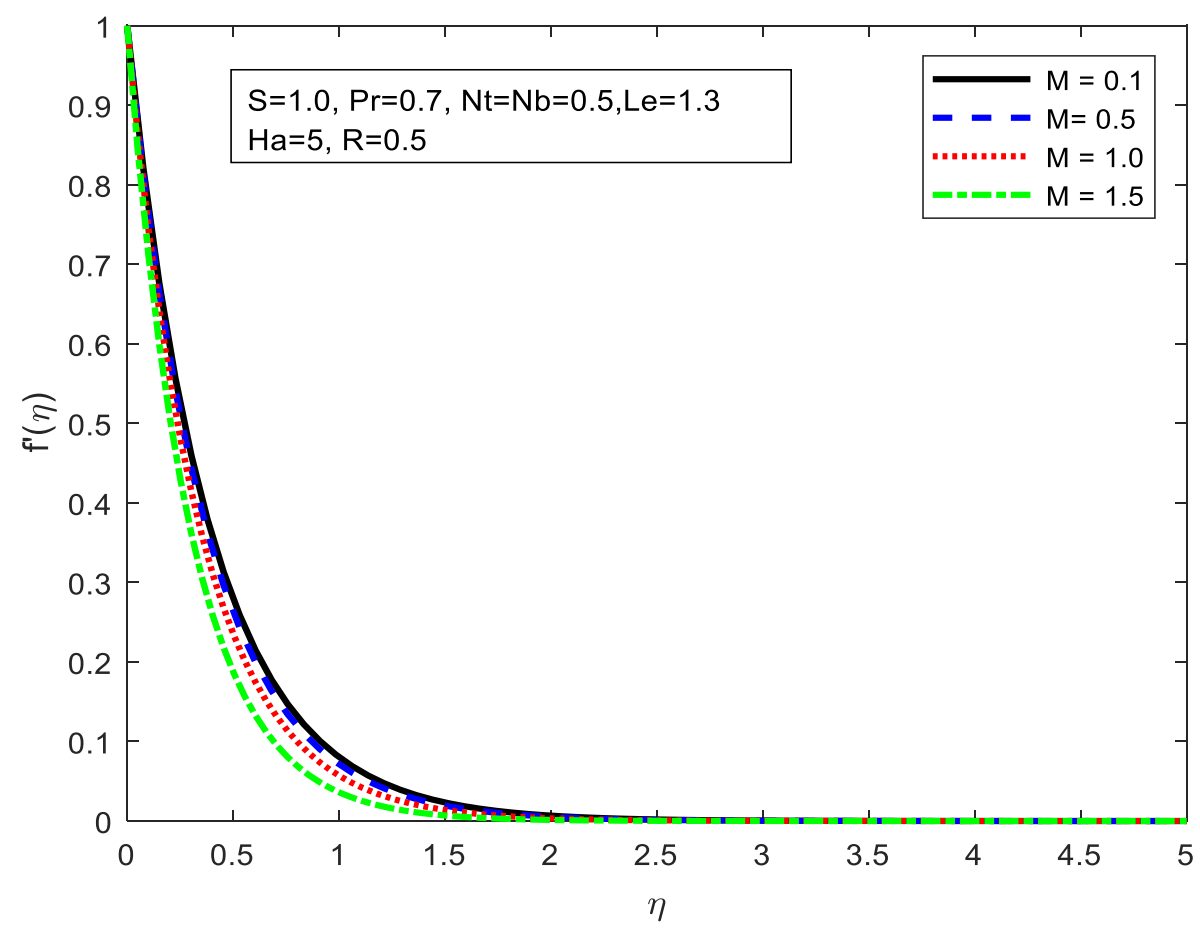

Fig 5. Influence of $M$ on Velocity Profiles 


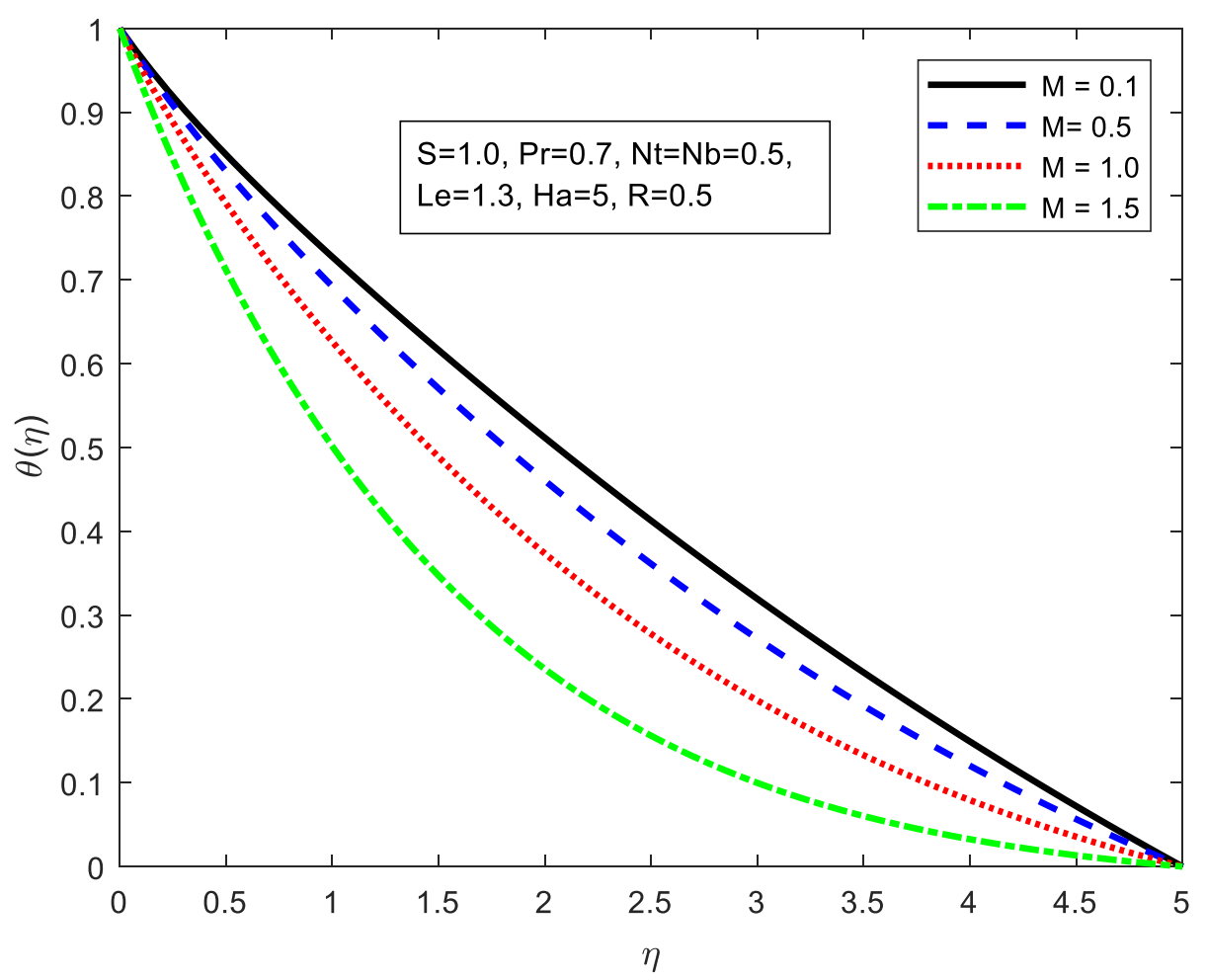

Fig 6. Influence of $M$ on Temperature Profiles

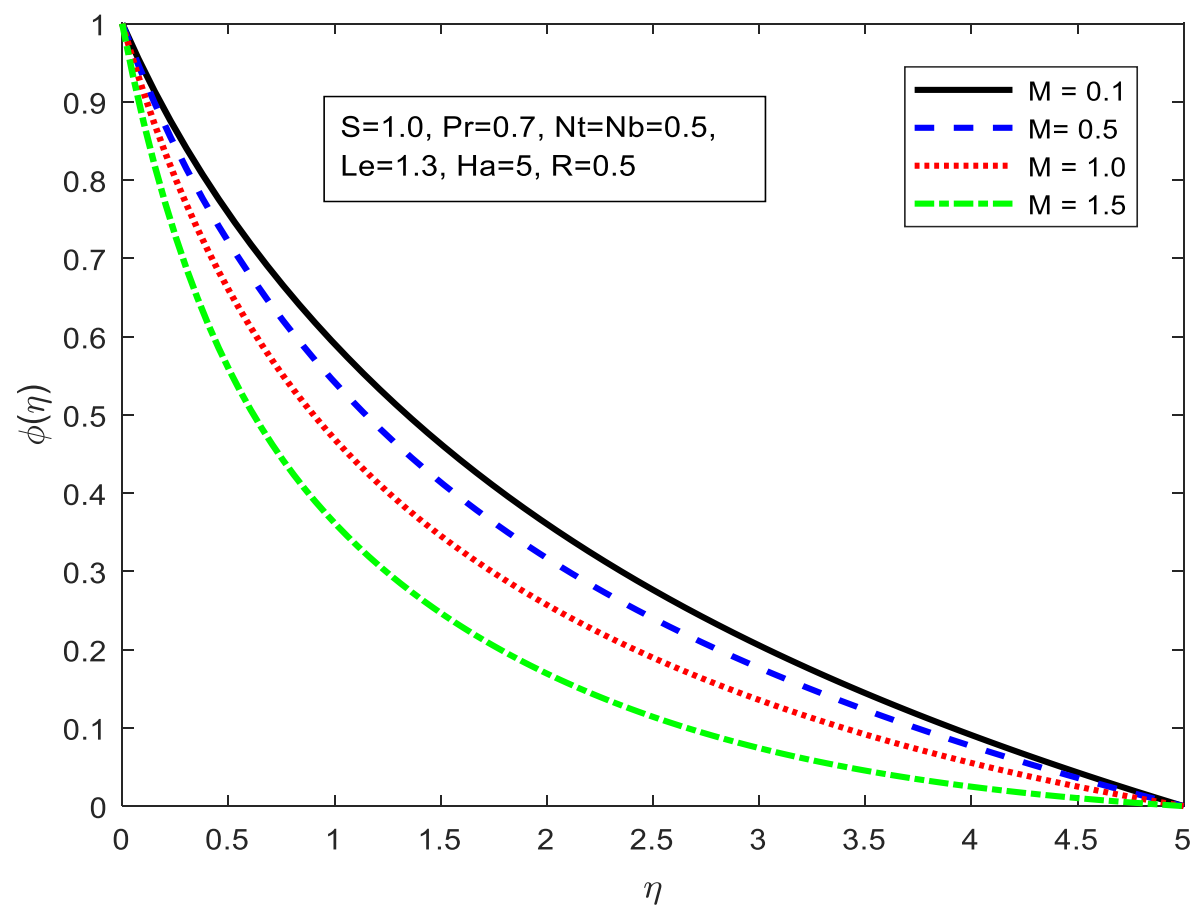

Fig 7. Influence of $M$ on Concentration Profiles 


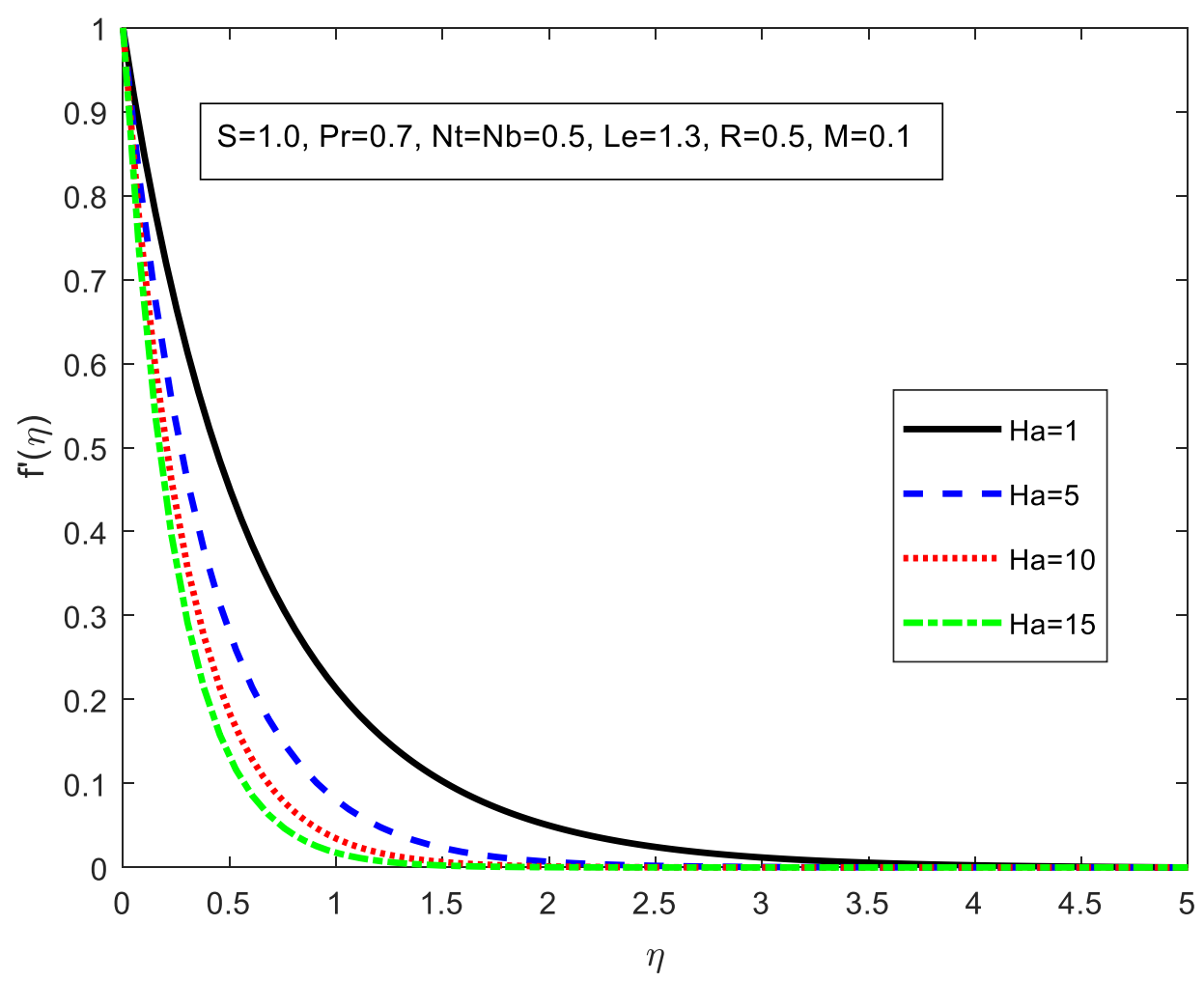

Fig 8. Influence of $\mathrm{Ha}$ on Velocity Profiles

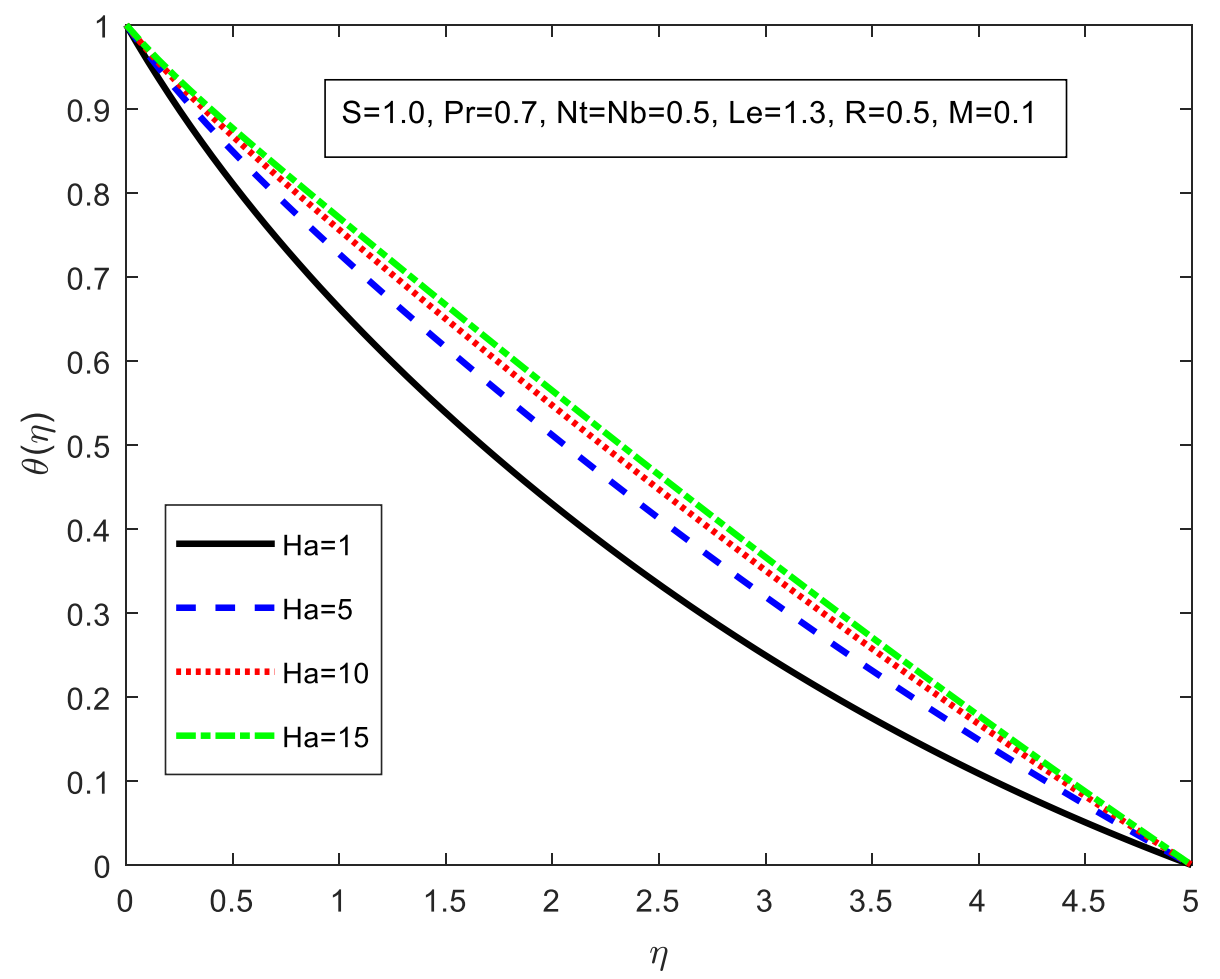

Fig 9. Influence of $H a$ on Temperature Profiles 


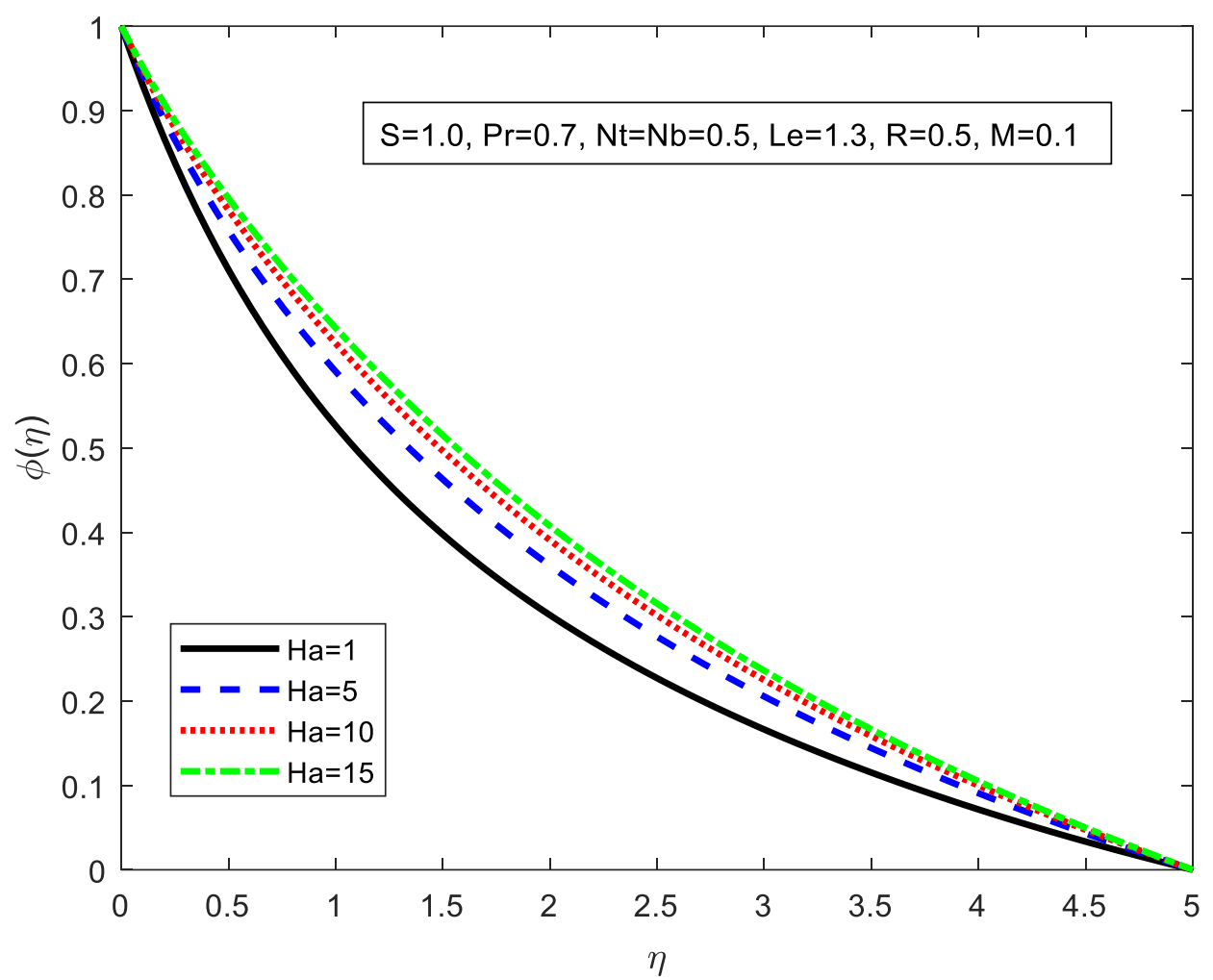

Fig 10. Influence of $\mathrm{Ha}$ on Concentration Profiles

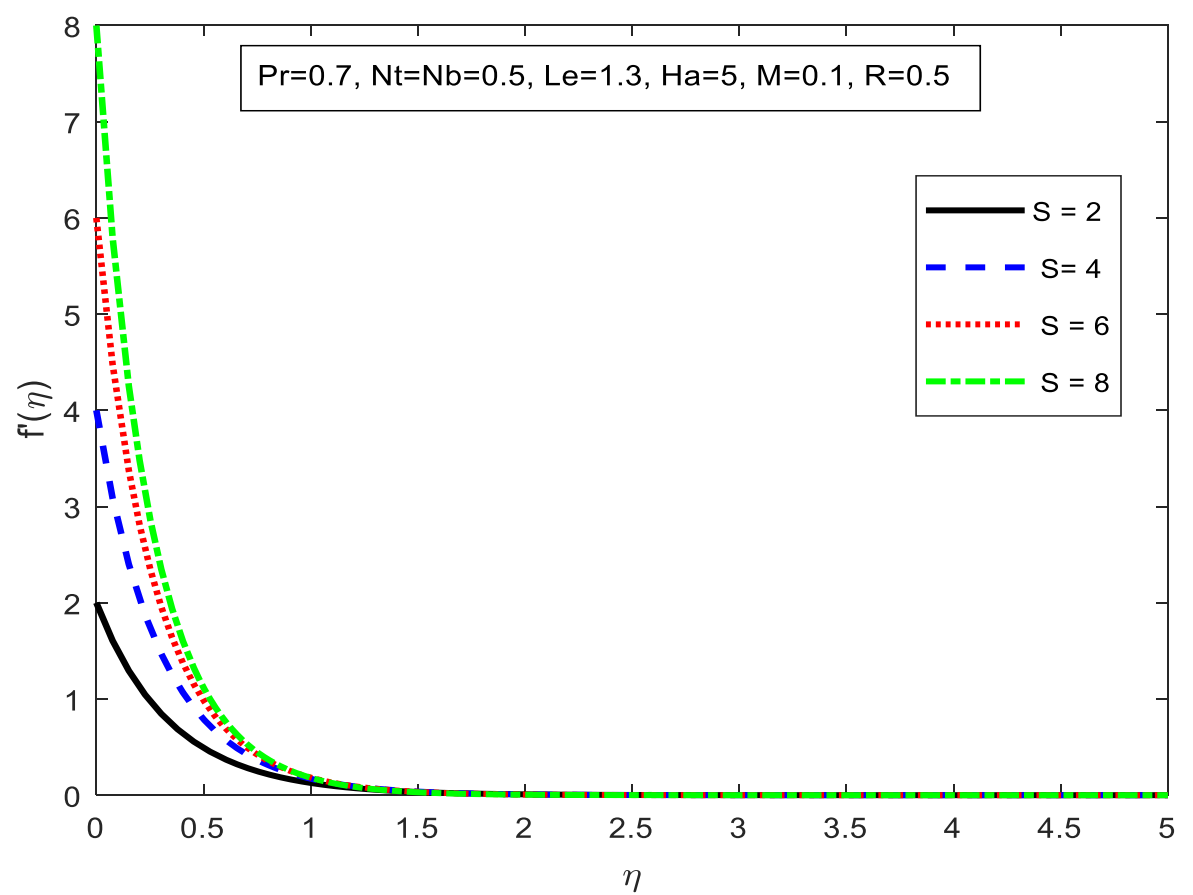

Fig 11. Influence of $S$ on Velocity Profiles 


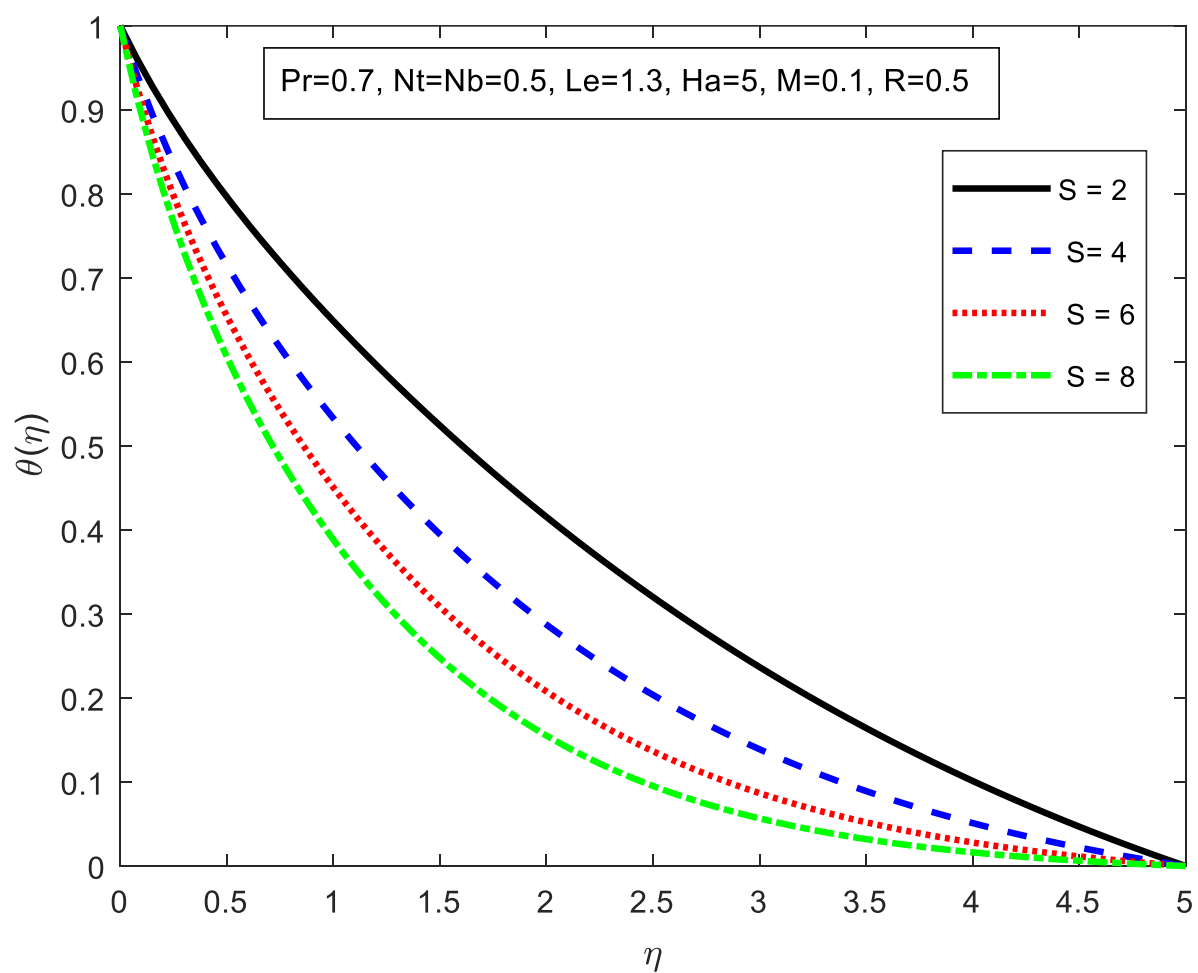

Fig 12. Influence of $S$ on Temperature Profiles

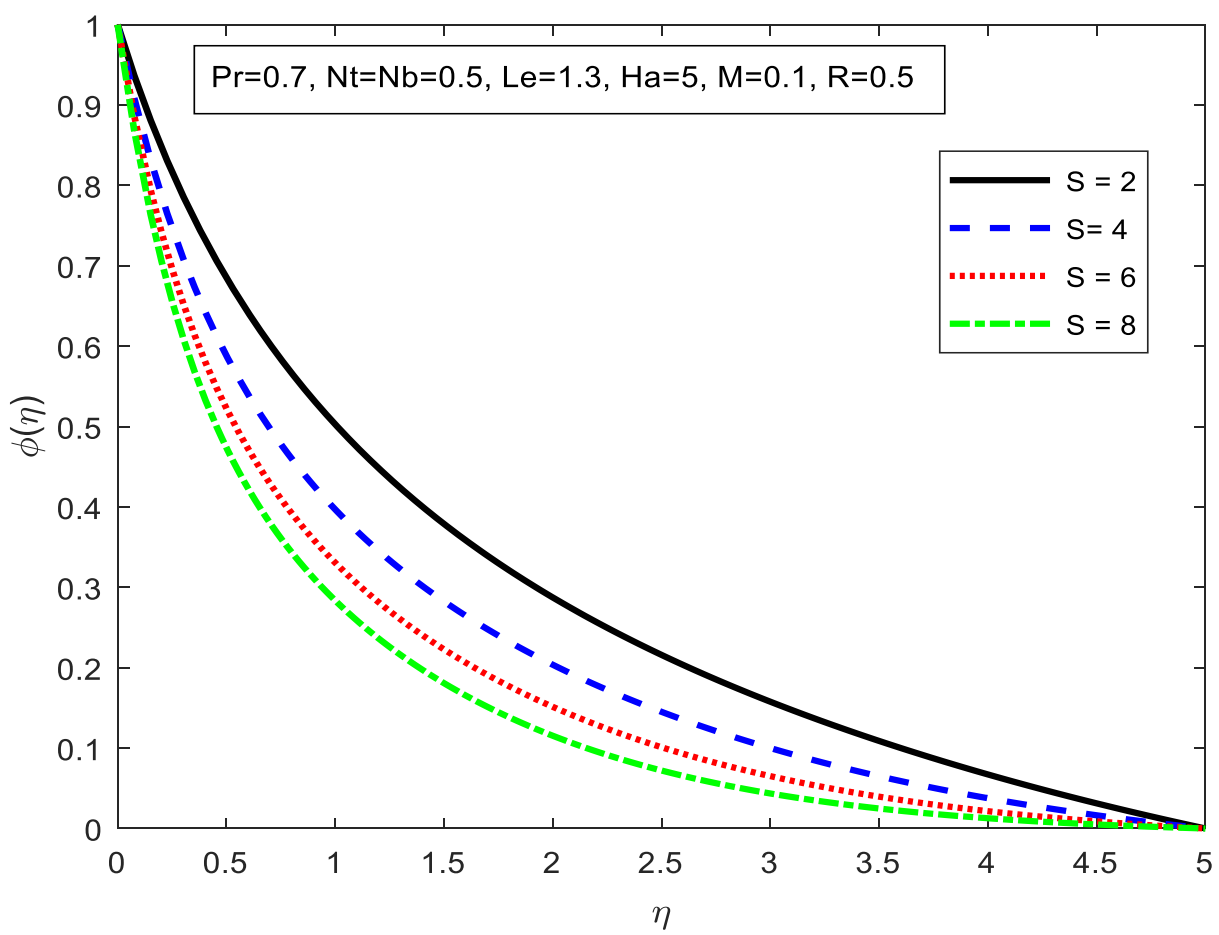

Fig 13. Influence of $S$ on Concentration Profiles 


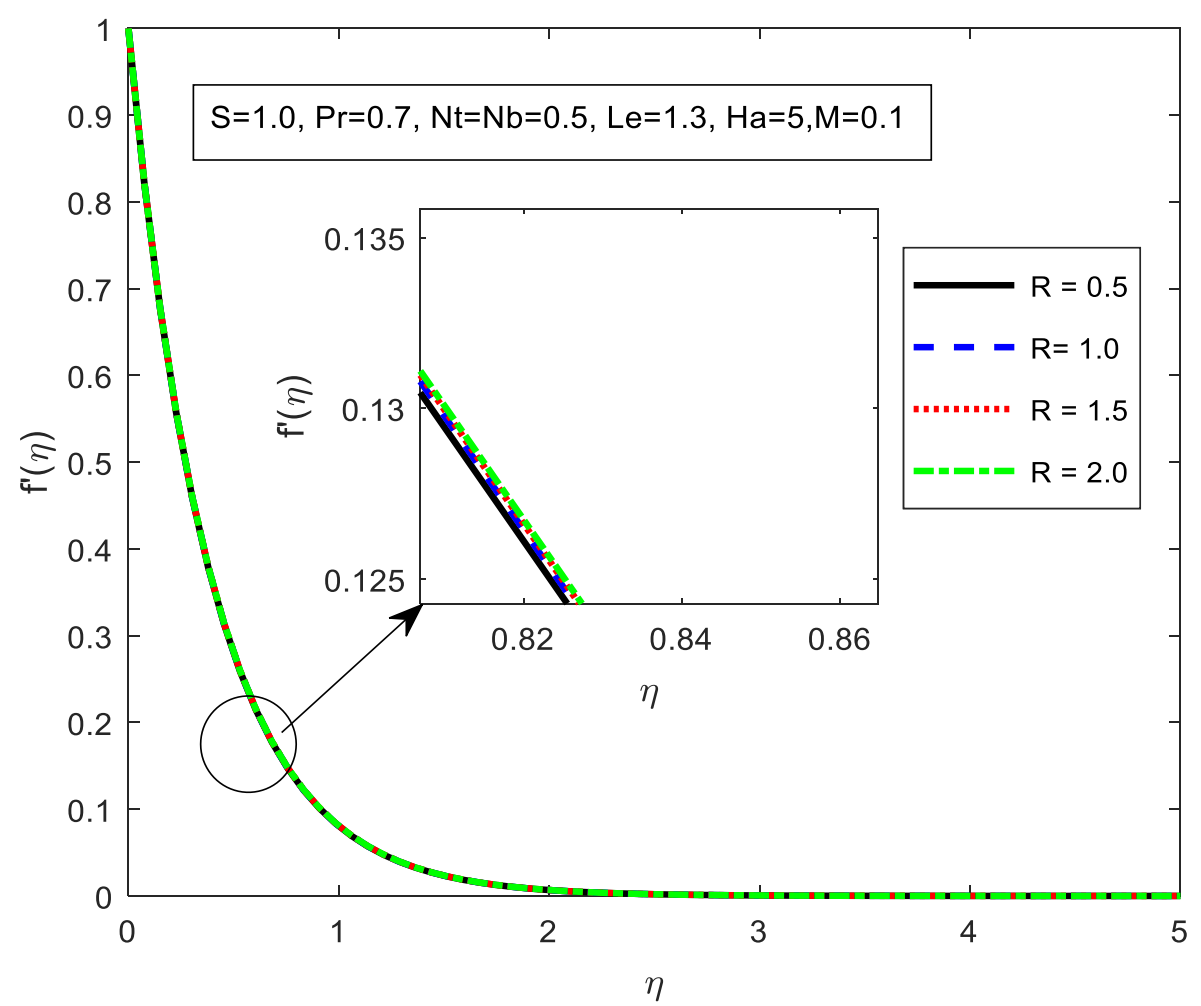

Fig 14. Influence of $R$ on Velocity Profiles

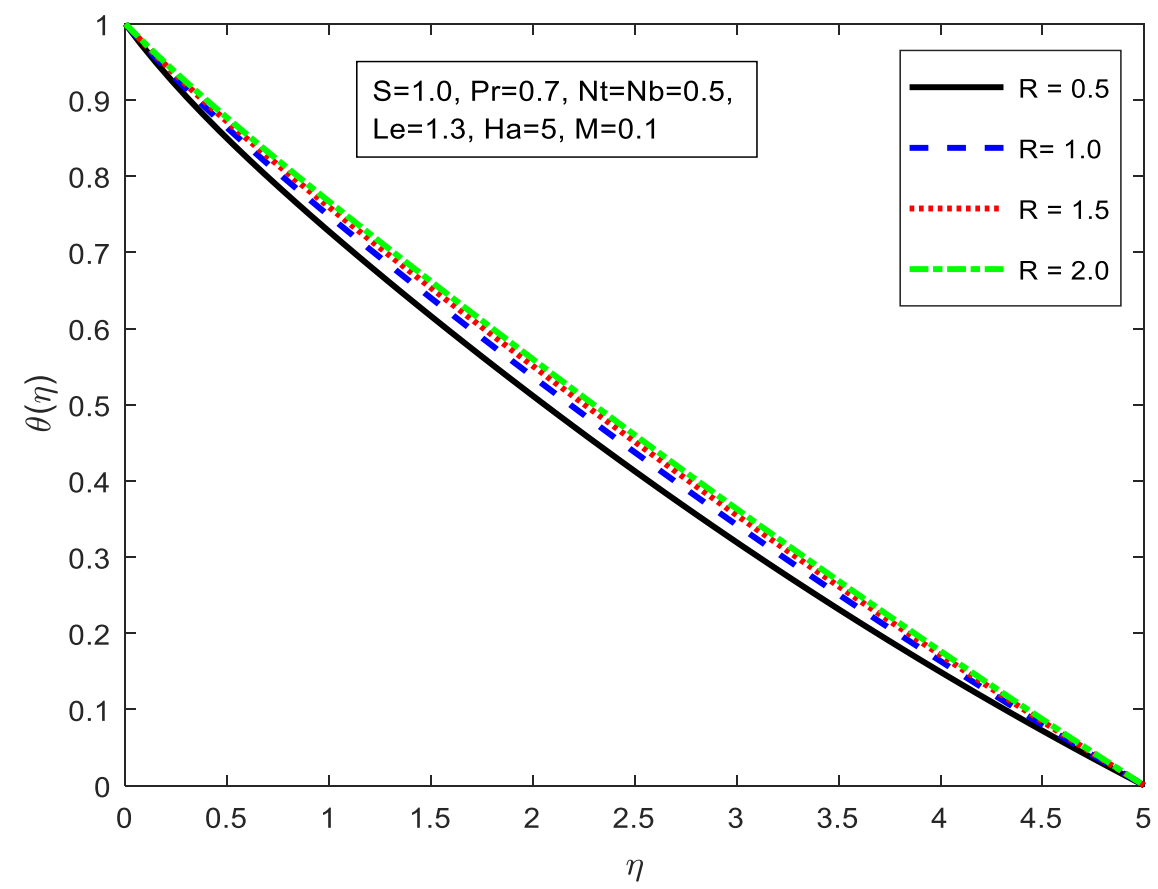

Fig. 15. Influence of $R$ on Temperature Profiles 


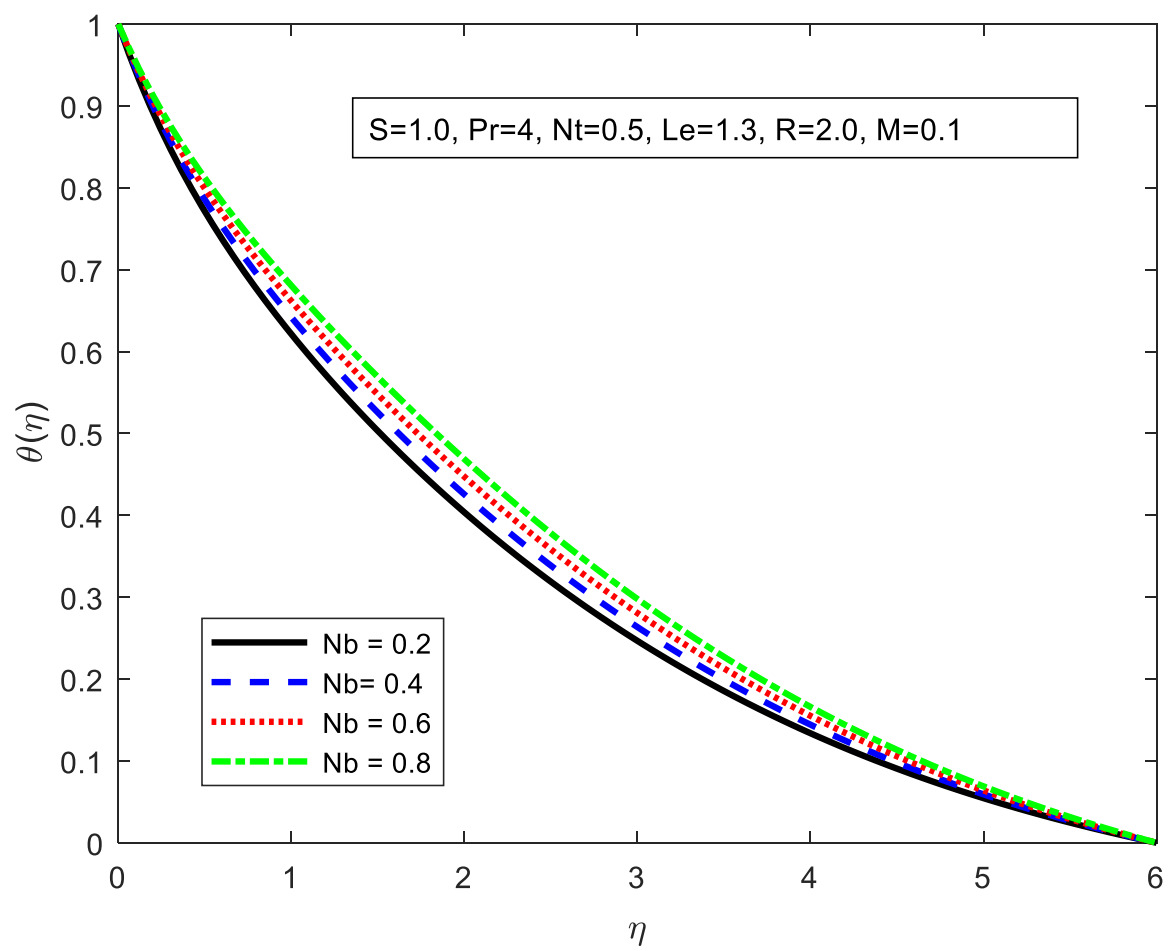

Fig. 16. Influence of $\mathrm{Nb}$ on Temperature Profiles

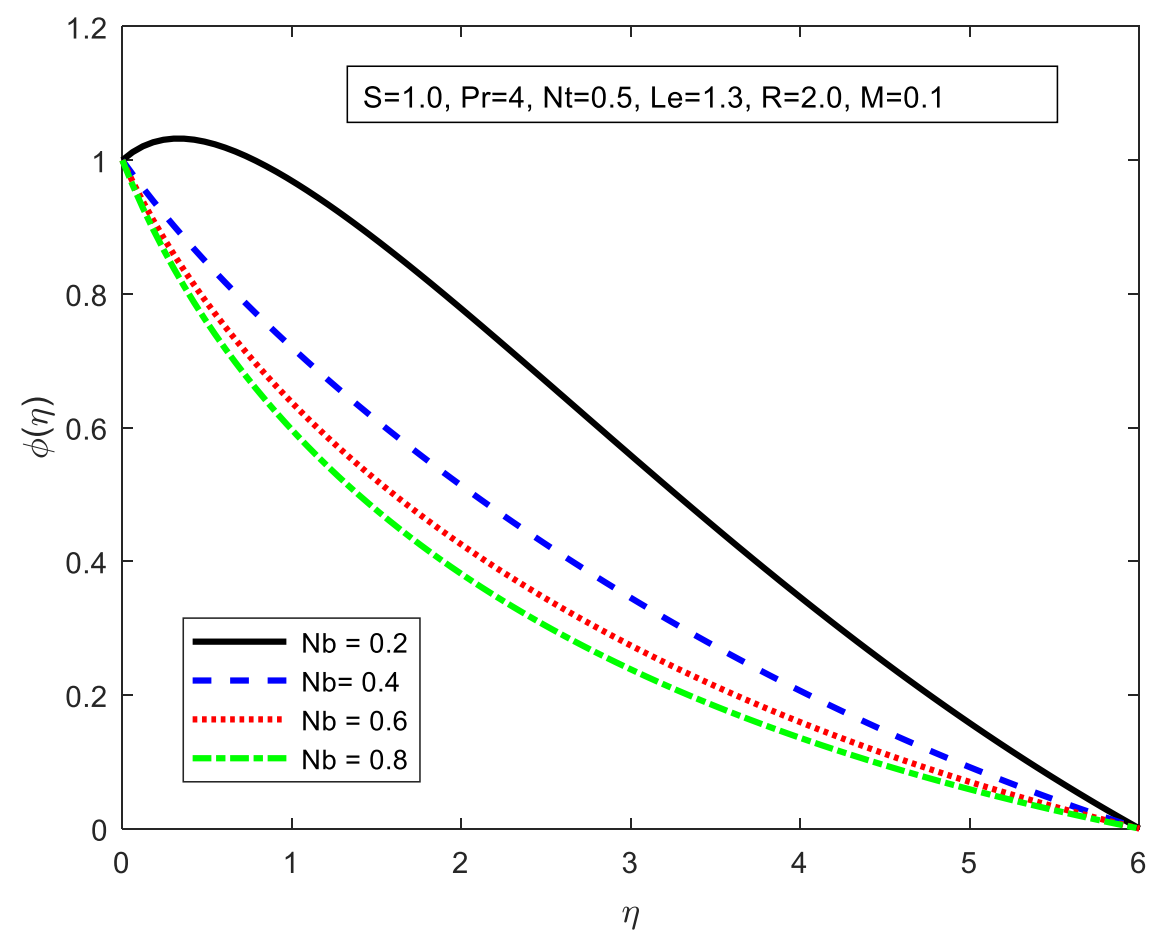

Fig. 17. Influence of $\mathrm{Nb}$ on Concentration Profiles 


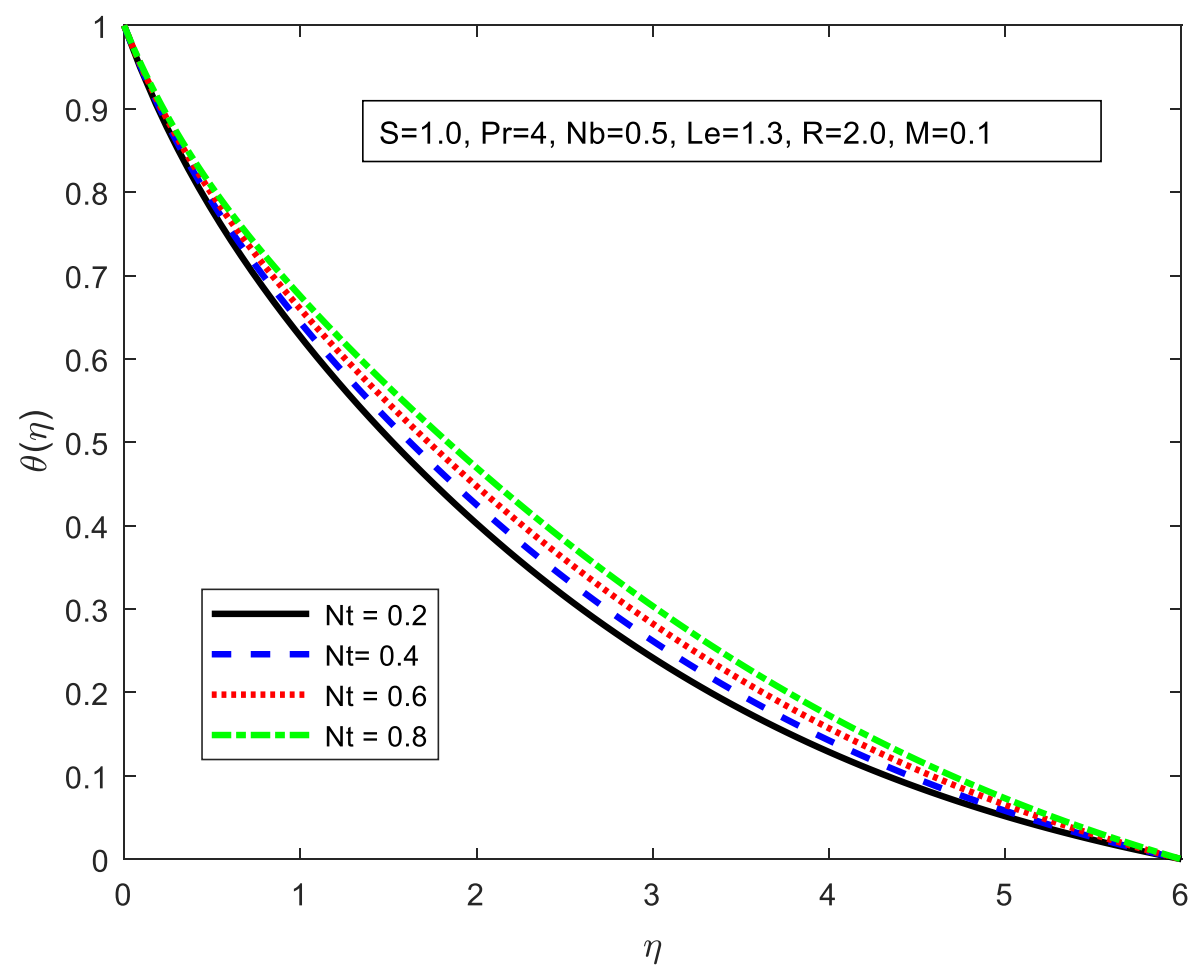

Fig. 18. Influence of $N t$ on Temperature Profiles

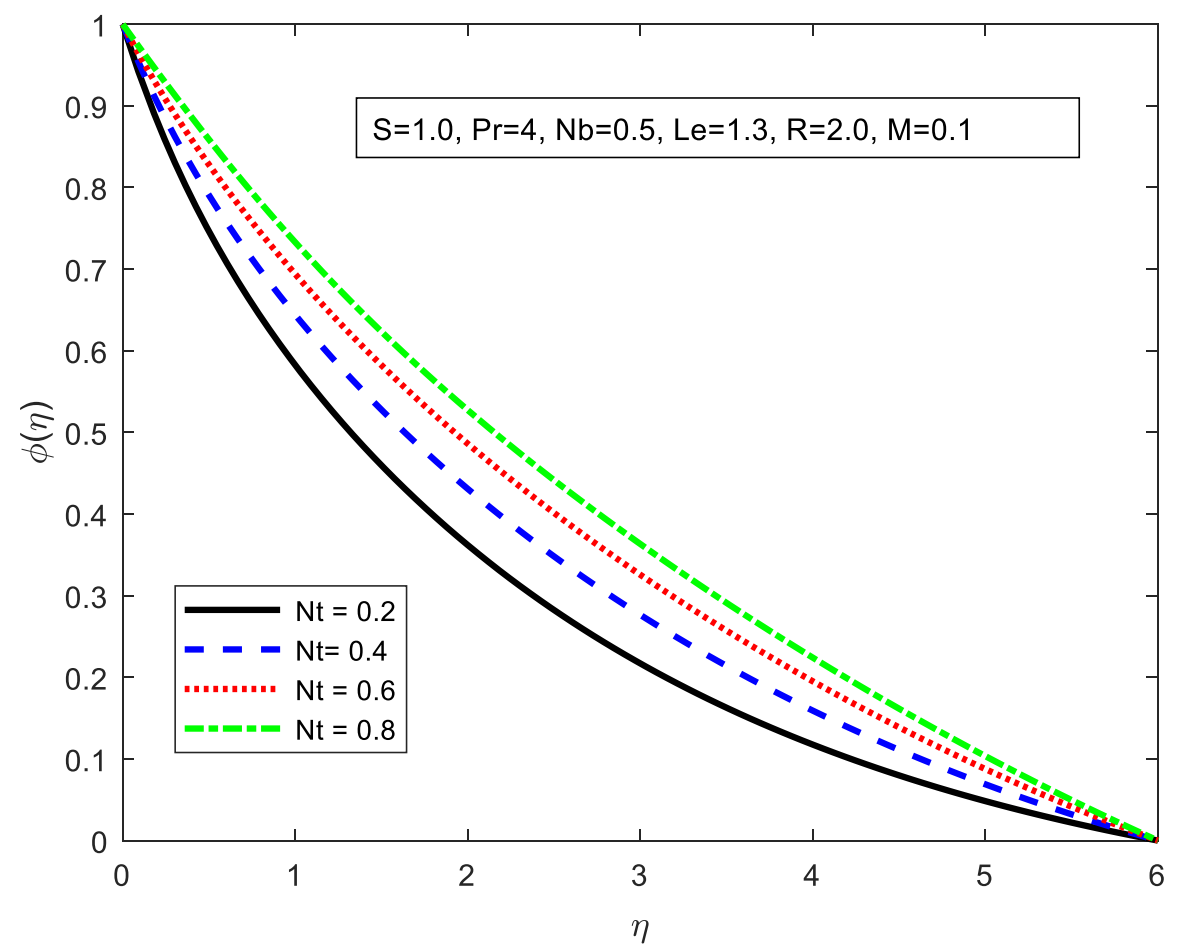

Fig. 19. Influence of $N t$ on Concentration Profiles 
Figs. 8 - 10 present the effects of velocity, temperature and nanoparticle volume fraction for various values of Hartmann number, $\mathrm{Ha}$. A significant deceleration in velocity is observed with increasing $\mathrm{Ha}$ values. Conversely temperature and nanoparticle volume fractions are slightly enhanced with increasing $\mathrm{Ha}$. The Hartmann number simulates the relative influence of Lorentzian magnetohydrodynamic drag force and viscous hydrodynamic force. As $\mathrm{Ha}$ rises, there is greater opposition to the flow which contributes to deceleration in the boundary layer. Stronger magnetic field therefore damps the flow and is utilized in industry for flow control. The additional work expended in dragging the magnetic nanofluid against the transverse magnetic field force induces heating in the nanofluid i.e. the kinetic energy is dissipated as thermal energy. This heat dissipation leads to an increase in temperature and thickening of the thermal boundary layer. The enhanced heating effect is also beneficial to the nanoparticle diffusion which is also enhanced. These patterns have also been reported by various other studies including Makinde et al [26] and Chamkha et al [27].

Figs. 11 - 13 present the effect of the transpiration i.e. suction/blowing parameter $(S)$ on velocity, temperature and nanoparticle volume fraction (concentration) profiles. The velocity is seen to increase with increasing $S$ values in particular in the vicinity of the wall and momentum boundary layer thickness is reduced. On the other hand, the temperature and nanoparticle volume fraction are lowered with increasing $S$. Stronger suction therefore discourages heat transfer from the surface to the ambient fluid which manifests in a cooling effect in the boundary layer. A thinner thermal boundary layer is produced. Similarly, migration of nanoparticles from the wall to the nanofluid is inhibited with stronger suction resulting in lower concentration magnitudes and a thinner concentration boundary layer. These observations also concur with other investigations including Khashiile et al. [8].

Fig. 14 - 15 visualize the effects of thermal radiation parameter, $R$, on velocity, temperature and nanoparticle volume fraction profiles. A very slight increase in velocity profiles is observed with increasing $R$ values. $R$ is the relative contribution of thermal radiative heat transfer to thermal conduction heat transfer. When $\mathrm{R} \rightarrow 0$, in Eqn. (8) radiative heat flux vanishes and purely forced convection is present. As the radiation parameter $R$ increases, the temperature profiles are observed to increase noticeably. For greater $R$ values, the thermal radiation dominates conduction. Consequently, higher $R$ values indicate larger quantity of radiative heat energy being introduced into the regime, resulting in an energization of the boundary layer and elevation in the temperature 
and heat transfer from the wall to the nanofluid. Thermal boundary layer thickness is therefore enhanced strongly with greater radiative parameter whereas there is a marginal thickening in momentum boundary layer thickness. Negligible influence on nanoparticle concentration is computed and therefore not shown. Furthermore, it is of note that the present model utilizes the Rosseland diffusion approximation and assumes the magnetic nanofluid is optically thick. This is a simple but acceptable approach in engineering simulation although alternative radiative flux models are being considered for future investigations to provide more refinement in optical properties of the nanofluid [28].

Figs. 16-17 illustrates the influence of Brownian motion parameter, $N b$ on temperature $(\theta)$ and nanoparticle volume fraction concentration $(\phi)$. A slight increase in temperature profiles is observed with an increase in $\mathrm{Nb}$ values. However, the nanoparticle volume fraction concentration is significantly reduced. Brownian motion is amplified with increasing $\mathrm{Nb}$ and also the size of the nanoparticles is altered which adversely affects their diffusion in the boundary layer. Nanoparticle concentration boundary layer thickness is therefore decreased. The heat diffusion however is encouraged with smaller nanoparticles (higher $\mathrm{Nb}$ values) which increases thermal boundary layer thickness, as noted in various studies including Keblinski et al [29, 30].

Fig. 18- 19 illustrates the effect of thermophoresis parameter, $N t$ on temperature and nanoparticle volume fraction through the boundary layer regime over the stretching sheet. The mobilization of nanoparticles towards a colder zone driven by a temperature gradient force is called thermophoresis. The parameter $N t$ therefore plays a significant role in modifying temperature and nanoparticle volume fraction. As the value of $N t$ increases, the nanofluid temperature and concentration are seen to be elevated. i.e. thermal and nanofluid volume fraction boundary layer thicknesses are increased. As $N t$ increases, the heat transfer away from the wall is boosted and this aggravates nanoparticle deposition away into the nanofluid region, increasing nanoparticle volume fraction (concentration) as shown in Fig.19.

\section{CONCLUDING REMARKS}

In this paper, motivated by simulating high-temperature magnetic nanomaterials processing flows, a mathematical model has been presented for steady-state magnetohydrodynamic (MHD) flow of electrically conducting nanofluid from an exponentially stretching/shrinking permeable sheet with melting (phase change) and radiative heat transfer. Wall 
mass flux i.e. suction and blowing (injection) and Buongiorno's nanofluid model are included. Rosseland's diffusion flux model is employed for thermal radiation. The transformed boundary value problem is solved numerically with the Newton-Fehlberg iteration technique. Verification of solutions with non-melting cases from the literature is conducted. The present simulations have shown that:

(i)Increasing magnetic field i.e. Hartmann number elevates nanoparticle concentration and temperature whereas it damps the velocity.

(ii)Higher values of melting parameter consistently decelerate the boundary layer flow and suppress temperature and nanoparticle concentration.

(iii)Higher radiative parameter strongly increases temperature (and thermal boundary layer thickness) and weakly accelerates the flow.

(iv)Increasing Brownian motion reduces nanoparticle concentrations whereas greater thermophoretic body force strongly enhances them.

(v)Increasing Hartmann number suppresses Nusselt number and Sherwood number whereas they are stronger wall suction and melting parameter enhance them.

(vi) Increasing thermophoresis enhances both temperature and nanoparticle volume fractions.

(vii) Increasing Prandtl number weakly increases velocity profile and nanoparticle volume fraction whereas it reduces temperature.

The present study has neglected non-Newtonian (rheological) effects [31] which will be considered in the future.

\section{REFERENCES}

[1] Choi, S.U.S.: Enhancing thermal conductivity of fluids with nanoparticles. Developments and Applications of Non-Newtonian Flows, American Society of Mechanical Engineers, New York, 99-10, 1994.

[2] Buongiorno, J, Convective transport in nanofluids, ASME Journal of Heat TransferTransactions of the ASME, 128(3), 240-250, 2006.

[3] Yang, C., Li, W., \& Nakayama, A., Convective heat transfer of nanofluids in a concentric annulus, International Journal of Thermal Sciences, 71, 249-257, 2013.

[4] S Abdul Gaffar, V Ramachandra Prasad, P Ramesh Reddy, B Md Khan, K Venkatadri, Magnetohydrodynamic non-Darcy flows of nanofluid from horizontal circular permeable cylinder: a Buongiorno's mathematical model, Journal of Nanofluids, 8, 1-11, 2019. 
[5] Abdullah Al-Mamun, S.M. Arifuzzaman, Sk. Reza-E-Rabbi, Pronab Biswas, Md. Shakhaoath Khan, Computational modelling on MHD radiative Sisko nanofluids flow through a nonlinearly stretching sheet, Int. J. Heat and Tech., 37, 1, 285-295, 2019.

[6] Natalia C. Roşca, Alin V. Roşca, Ioan Pop, Unsteady separated stagnation-point flow and heat transfer past a stretching/shrinking sheet in a copper-water nanofluid, Int. J. Num. Methods Heat Fluid Flow, 2019. https://doi.org/10.1108/HFF-09-2018-0527

[7] D. Srinivasacharya, Md. Shafeeurrahman, Joule heating effect on entropy generation in MHD mixed convection flow of chemically reacting nanofluid between two concentric cylinders, Int. $J$. Heat and Tech., 35, 487-497, 2017.

[8] Najiyah Safwan Khashiile, Norihan Md Arifin, Ezad Hafidzuddin and Nadihah Wahi, Dual stratified nanofluid past a permeable shrinking/stretching sheet using a Non-Fourier energy model, Applied Science, 2019, 9, 2124. doi:10.3390/app9102124

[9] P. Sreenivasulu, T. Poornima and N. Bhaskar Reddy, Thermal Radiation effects on MHD boundary layer slip flow past a permeable exponential stretching sheet in the presence of Joule heating and viscous dissipation, J. Applied Fluid Mechanics, 9, 1, 267-278, 2016.

[10] Atul Kumar Ray, Vasu B., O. Anwar Bég, R.S.R. Gorla, P.V.S.N. Murthy, Magnetobioconvection flow of a Casson thin film with nanoparticles over an unsteady stretching sheet: HAM and GDQ computation, Int. J. Numerical Methods for Heat \& Fluid Flow, 2019. https://doi.org/10.1108/HFF-02-2019-0158

[11] Sudipta Ghosh, Swati Mukhopadhyay, Flow and heat transfer of nanofluid over an exponentially shrinking porous sheet with heat and mass fluxes, Propulsion and Power Research, 7(3), 268-275, 2018.

[12] Adigoppula Raju, Odelu Ojjela, Pravin Kashyap Kambhatla, The combined effects of induced magnetic field, thermophoresis and Brownian motion on double stratified nonlinear convectiveradiative Jeffrey nanofluid flow with heat source/sink, J. Analysis, 2019. https://doi.org/10.1007/s41478-019-00187-z.

[13] M. Ijaz Khan, Sohail A. Khan, T. Hayat, A. Alsaedi, Entropy Optimization in magnetohydrodynamic flow of third-grade nanofluid with viscous dissipation and chemical reaction, Iranian J. Sci. and Tech., Transactions A: Science, 2019. https://doi.org/10.1007/s40995019-00728-y

[14] S.P. Anjali Devi, P. Suriyakumar, Effect of magnetic field on Blasius and Sakiadis flow of nanofluids past an inclined plate, J. Taibah University for Science, 11, pp.1275-1288, 2017.

[15] NurArdianaAmirsom, Md. Jashim Uddin, Md Faisal Md Basir, Ali Kadir, O. Anwar Bég and Ahmad Izani Md. Ismail, Computation of melting dissipative magnetohydrodynamic nanofluid bioconvection with second-order slip and variable thermophysical properties, Applied Sciences, 2019, 9, 2493, doi:10.3390/app9122493.

[16] T. Hayat, K. Muhammad and A. Alsaedi, Melting effect in MHD stagnation point flow of Jeffrey nanomaterial, Physica Scripta, 2019. https://doi.org/10.1088/1402-4896/ab210e 
[17] Waqar Azeem Khan, Masood Khan, Muhammad Irfan, A.S. Alshomrani, Impact of melting heat transfer and nonlinear radiative heat flux mechanisms for the generalized Burgers fluids, Results in Physics, 7,.4025-4032, 2017.

[18] Feroz Ahmed Soomro, Muhammad Usman, Rizwan Ul Haq, Wei Wang, Melting heat transfer analysis of Sisko fluid over a moving surface with nonlinear thermal radiation via collocation method, Int. J. Heat and Mass Transfer, Vol. 126, pp.1034-1042, 2018.

[19] Y. Zhang et al., Fabrication of ZnCoS nanomaterial for high energy flexible asymmetric supercapacitors, Chemical Engineering Journal, 374, 347-358, 2019.

[20] Jortner J, Rao CNR. Nanostructured advanced materials. Perspectives and directions, Pure Appl Chemistry, 74, 1491-1506, 2002.

[21] Ishak, A. (2011). MHD boundary layer flow due to an exponentially stretching sheet with radiation effect. Sains Malaysiana, 40, 391-395.

[22] Swati Mukhopadhyay and Rama Subba Reddy Gorla, Effects of partial slip on boundary layer flow past a permeable exponential stretching sheet in the presence of thermal radiation. Heat Mass Transfer 45, 1447-1452, 2009.

[23] Prasad V. R., Vasu B., Anwar Bég O. and Rana D. Prashad, Thermal radiation effects on magnetohydrodynamic free convection heat and mass transfer from a sphere in a variable porosity regime, Communications in Nonlinear Science and Numerical Simulation, 17(2):654-671, 2012.

[24] D. Incropera and D. DeWitt, Fundamentals of Heat and Mass Transfer, Wiley, 1981.

[25] H. Schlichting, Boundary-Layer Theory, $8^{\mathrm{TH}}$ Edn, Mac-Graw-Hill, New York, 2000.

[26] O. D. Makinde, K. Zimba, O. Anwar Bég, Numerical study of chemically reacting hydromagnetic boundary layer flow with Soret/Dufour effects and a convective surface boundary condition, Int. J. Thermal and Environmental Engineering, 4, 89-98, 2012.

[27] A. J. Chamkha, M. Mujtaba, A. Quadri, and C. Issa, Thermal radiation effects on MHD forced convection flow adjacent to a non-isothermal wedge in the presence of a heat source or sink, Heat and Mass Transfer, 39, 305-312, 2003.

[28] S. Kuharat, O. Anwar Bég, A. Kadir and M. Shamshuddin, Computational study of heat transfer in solar collectors with different radiative flux models, Heat Transfer Asian Research, 130, 2019. DOI: 10.1002/htj.21418 (30 pages)

[29] Keblinski, P., Nanofluids for enhanced thermal transport: understanding and controversy. In Symposium II Nanoscale Heat Transport_From Fundamentals to Devices, Materials Research Society Spring Symposium, New York, USA, 2007:10-13

[30] Keblinski, P., Phillpot, S. R., Choi, S. U. S., \& Eastman, J. A., Mechanisms of heat flow in suspensions of nano-sized particles (nanofluids). International Journal Heat Mass Transfer, 45(4):855-863, 2002.

[31] N. Shukla, Puneet Rana, O. Anwar Bég, Unsteady MHD non-Newtonian heat transfer nanofluids with entropy generation analysis, Nonlinear Engineering - Modeling and Application, 8: 630-644, 2019. 